\title{
EXPLORING THEMES OF TIBETAN CULTURAL IDENTITY DURING THE SETTLEMENT EXPERIENCE IN TORONTO, CANADA
}

By

Farha Akhtar, B.A. (Journalism and Communications), University of Regina, 1999

\author{
A Major Research Paper \\ Presented to Ryerson University
}

in partial fulfillment of the requirements for the degree of

Master of Arts

in the program of

Immigration and Settlement Studies

Toronto, Ontario, Canada, 2010

(C) Farha Akhtar 2010 


\section{Author's Declaration}

I hereby declare that I am the sole author of this major research paper.

I authorize Ryerson University to lend this paper to other institutions or individuals for the purpose of scholarly research.

I further authorize Ryerson University to reproduce this paper by photocopying or by other means, in total or in part, at the request of other institutions or individuals for the purpose of scholarly research. 
EXPLORING THEMES OF TIBETAN CULTURAL IDENTITY DURING THE SETTLEMENT EXPERIENCE IN TORONTO, CANADA

\author{
Farha Akhtar \\ Master of Arts, 2010 \\ Immigration and Settlement Studies \\ Ryerson University
}

\begin{abstract}
This study explores both existing research as well as emerging themes in the area of Tibetan exile communities. Previous research examining the settlement experiences of Tibetan refugees in Europe, the United States and India has focused largely on the various ways in which individuals acculturate and adapt to new, culturally different environments. Out of this research, a number of themes arise such as cultural expectations, internal concepts of identity, and citizenship. Authors have suggested that Tibetan refugees during settlement are likely to adopt a version of Berry's integration strategy of acculturation. What is lacking in these earlier studies is an exploration of the experiences of Tibetan refugees in Canada. This study is set within a Canadian context and considers other social factors that may greatly influence the settlement experience, namely barriers to settlement such as the failure to have foreign credentials recognized.
\end{abstract}

Key words: Tibetan, Refugees, Settlement, Acculturation, Cultural Identity 


\section{Acknowledgments}

I am grateful to my MRP supervisor Dr. Carmen Schifellite, whose guidance, patience and superb copy-editing skills were invaluable during the research and writing process.

I would also like to thank my second-reader Dr. Vappu Tyyskä for introducing me to the work of John Berry and for helping expose me to the pressing issues affecting disenfranchised migrant populations in Canada.

This paper could not have been produced without the assistance of Tenzin Gethoktsang and Sonam Dekyi who graciously provided valuable insight as well as connections to Toronto's Tibetan community. I would also like to thank each of the study participants for accommodating my research needs and tight schedules. Your willingness to share your experiences and personal stories will always be remembered. Your resilience, has provided me with a greater appreciation of the struggles of refugees worldwide.

Special appreciation goes to Prof. Pramila Aggarwal and my friend and classmate Shelley Hasho for additional support and inspiration.

This paper is dedicated to my husband Adam Clarkson. 


\section{Table of Contents}

Page

1. Introduction 1

2. Review of the Literature 3

Theoretical Overview 3

Terminology 5

Historical Context: The Tibetan Refugee Diaspora 8

Retaining and Sustaining a Cultural Legacy in Exile 10

- Cultural Ambassadors 11

Existing Research on Strategies of Acculturation for Tibetans in Exile 13

$\begin{array}{ll}\text { Citizenship } & 20\end{array}$

Tibetan Identity and "Tibetanness" 23

Internal Concepts 23

Western Ideals of Tibetanness 25

Obstacles in the Settlement Process $\quad 27$

Implications for My Research $\quad 30$

3. Methodology and Research Design 32

Research Design 33

$\begin{array}{ll}\text { Theoretical Framework } & 33\end{array}$

$\begin{array}{ll}\text { Ethical Considerations } & 34\end{array}$

$\begin{array}{ll}\text { Participant Selection } & 36\end{array}$

$\begin{array}{ll}\text { Participant Demographics } & 38\end{array}$ 
4. Results and Analysis

Expectations of Cultural Ambassadorship

Citizenship

Strategies of Hybrid Acculturation

Cultural Expectations

Push and Pull Factors that Influence Strategies of Acculturation

Familial Separation and feelings of Displacement

55

Lack of Credential Recognition as a Barrier Settlement

Social Support Systems

Acculturation Strategies

62

5. Discussion

Assessing Berry's Integration Strategy

Barriers to Settlement: Credential Recognition

67

6. Study Strengths, Limitations and Further Study

Recommendations

7. References

72

List of Appendices

Appendix A: Recruitment Flyer

Appendix B: Consent Form

Appendix C: Interview Guide 


\section{Chapter 1: Introduction}

Tibetans living in exile have provided social scientists with a unique lens through which to view the impact that prolonged displacement can have on generations living in exile. Of particular interest to many researchers are the ways in which the collective efforts of cultural preservation as well as efforts to maintain cultural cohesion among Tibetan communities that lay scattered across South Asia, Europe and North America might have an impact and or influence individual identity during the experience of re-settlement. The ties that bind individuals in the Tibetan diaspora, their religion, their culture, and their political aspirations for an independent and free Tibet combine to make what Houston and Wright (2003) describe as a type of "Grand Narrative" of Tibetan diasporic nationalism (Houston \& Wright, 2003, 218). It is a powerful narrative that has helped unify and galvanize the global Tibetan exile community. It keeps alive a culture and traditions Tibetan exiles fear might otherwise be lost as result of the Chinese invasion and occupation of their homeland and the continuous exodus of the Tibetan population from Tibet. Yet, as these and other authors have argued, this grand narrative has a way of homogenizing identities (Houston \& Wright, 2003, 217). The Tibetan government in exile has encouraged Tibetans in the diaspora to take utmost care in actively preserving the various facets of their culture whether it be language, religion or behavior to avoid complete assimilation in their new country. At the same time, diasporic Tibetans are encouraged to adapt to their new surroundings wherever their life in exile might be. Thus cultural preservation has become a paramount concern in the lives of 
many Tibetan people.

Yet as some researchers have argued, the very notion of preserving culture is a problematic one in that it assumes culture can be "mapped, practiced and preserved" (Anand, 2000, 278). Yet, as Anand argues, culture cannot be essentialized in this way because it is a concept that is socially and politically contested (Anand, 2000, 278). Therefore it is argued that during the settlement experience in particular, the cultural identity of an individual is likely to transform and evolve during the adaptation process rather than remain in a fixed state.

The focus of this study is to examine the acculturation process of Tibetan refugees between the ages of 20 and 40 who have migrated to and have settled in the culturally pluralistic setting of Toronto, Canada. It will examine the meaning individuals ascribe to their culture, the way they perceive and describe their own cultural identity, and the role that culture plays in their day-to-day lives as they move through the settlement process. Data was gathered through in-depth personal interviews with five Tibetan men and women who claimed refugee status upon arrival in Canada. These interviews serve to offer a snapshot of the different dynamics that can be constantly at play during the settlement experience. 


\section{Chapter 2: Review of the Literature}

Theoretical Overview

From the onset of this study of Tibetan refugees living in exile, it was important to adopt a theoretical approach that could help open up avenues of inquiry during interviews with participants and aid in the analysis of the findings. John Berry's (2007) model of acculturation provides a very useful theoretical understanding of the various processes through which individuals adapt to their new surroundings. His theory of acculturation describes the "cultural and psychological change in cultural groups, families and individuals following intercultural contact" (Berry, 2007, 69). He explains that acculturation can take place in a number of circumstances including during colonization, military invasion, or migration, and that upon entry into a culturally plural society, ethnocultural communities will often maintain features of their own heritage (Berry, 2007, 70).

Berry has identified four different strategies of acculturation which he lists as; integration, assimilation, separation and marginalization. These acculturation strategies greatly differ. For example, if individuals do not desire to maintain their cultural identity but rather seek daily interactions with other cultures then they adopt an assimilation strategy. Whereas when individuals place importance to upholding their original culture but avoid interaction with others they adopt a strategy of separation, and when there is little interest in either cultural maintenance or having relations with others then the strategy adopted is marginalization (Berry, 2007, 72). 
Of the four acculturation strategies, Berry identifies one strategy as being both the most prevalent and the most successful both psychologically and socioculturally and that is the strategy of integration (Berry, 2007, 69). According to Berry, individuals who follow the avenue of integration prefer to maintain their own cultural heritage yet also seek to participate and engage in the life of the larger society. The ability to achieve this balance is seen as positive settlement.

A weakness with Berry's model of acculturation is the way it assumes acculturation takes place in only one of these four ways. As other researchers such as Netting (2001) have pointed out, it is possible for individuals to move through different acculturation strategies during settlement without limiting themselves to just one. In some instances, combining strategies may also prove useful in a particular circumstance. For example, Netting's study of South Asian youth and marriage shows individuals use a modernization-assimilation strategy when approaching relationships, meaning they blend Indian traditional marriage systems with North American dating practice $(2001,141)$. What Berry's models do offer however, is a very useful way of understanding the processes of how individuals adapt to a new country. Thus this theoretical model can be quite valuable in a study such as this, particularly if we recognize that individuals can reconcile cultural differences and negotiate differences by adopting different strategies of acculturation.

Researchers studying the settlement experience of migrants have found it useful to study the various processes of acculturation because they reveal valuable information about the different ways ethnocultural groups and 
individuals engage with each other and more importantly, the transformations they undergo as result of these interactions. It is important to note, that settlement itself is an ongoing and multi-faceted experience and just one aspect of the larger migration experience. An examination of the acculturation processes which Tibetans in exile adopt is particularly interesting given their migration path often involves multiple countries and multiple societies. Canada may be the second or third country of settlement for a Tibetan exile after having spent some years in India, Nepal, Bhutan or the United States. Another unique feature about this group that makes it an interesting one to study, is the way culture preservation efforts might influence the settlement experience. One of the aims of this study has been to identify what acculturation strategy the study informants were adopting through these various stages of settlement and re-settlement as well as to gain some understanding as to why they chose the acculturation strategies they did.

\section{Terminology}

Before a thorough exploration of Tibetan acculturation could be conducted, it was important to identify some of the essential terminology that consistently appears in the literature on Tibetan exiles and determine what definitions would be useful to adopt in this examination. Some of those key concepts include settlement, cultural identity, refugee and refugee diaspora.

Two common terms which frequently appear in the literature focusing on immigration and migration are settlement and resettlement. Settlement can be 
understood as the process of migrating to a new place and the re-establishing of life in a new setting. It can be seen as a type of transition that occurs as one moves from one environment to another picking up knowledge and skills, becoming self-sufficient and communicating and interacting with members of his or her new society (Citizenship and Immigration Canada, 1995 as cited by Leung, $2000,8)$. As Leung points out, an individual's settlement experience may also involve multiple domains, as is the case with refugees. Thus, resettlement can also be understood in these terms since it shares many of the same elements of settlement in that it involves adjusting, adapting and integrating to a new environment (Holder, 1999, II-1 as cited by Leung, 2000). Quite often these two terms are used interchangeably. This study will utilize both terms with the understanding that they share a similar meaning.

In studying the settlement and resettlement experience of any group or individual it is important to recognize whether their migration was voluntary or involuntary in nature. Involuntary or forced migration is assumed to have a political dimension to it, and is based on flight from persecution whereas voluntary migration is assumed to be influenced by economic motivations (Betts, 2009 , 4). Generally speaking, this criterion has been used to differentiate immigrants from refugees. However, as Betts is quick to point out it is highly problematic to attempt to classify individuals as being in either one of these fixed categories. Most migration he argues, includes elements of both volition and coercion, as well as political and economic factors (Betts, 2009, 4). Nevertheless, it is important to make some distinction between immigrants and refugees for the 
purpose of this paper. We can therefore acknowledge these problematic definitions and understand refugees as a category of forced migration which according to the 1951 UN convention on the Status of Refugees is defined as people who "owing to a well-founded fear of persecution, on the grounds of race, religion, nationality or membership to a social group, find themselves outside of their country of origin, and are unable or unwilling to avail themselves of the protection of that country" (Article 1a of the 1951 Convention on the Status of Refugees as cited by Betts, 2009, 5).

Just as lives are re-established in new and different surroundings, so too are social networks and communities. Even in instances when individuals are forcibly displaced from their homelands, they can establish social, cultural and political formations in exile. These formations are what Cheran (2006) defines as diaspora. Tibetans in exile constitute a refugee diaspora in that their forced displacement was result of conflict and persecution in Tibet, which forced them to flee the place where they had established long-standing political, economic and cultural ties (Bose, 2006, 59).

As this examination reveals, culture, and specifically the cultural life of Tibetan refugees can play a significant role in the settlement process. For the purposes of this paper, Goodenough's (1971) anthropological definition of culture was adopted. It is explained as, "ways of perceiving, believing, evaluating, and behaving which are learned from and shared by a group of people" (Goodenough, 1971 as cited by Phuntsog, 1998, 37). One's cultural identity is thus shaped from sharing patterns of behavior with other members of one's 
cultural group (Phuntsog, 1998, 37). An individual's cultural identity reflects both their membership to a particular social group(s) as well as the "value and the emotional significance attached to that membership" (Tajfel, 1981, p. 255 as cited by Yang et al. p. 911).

The process of formulating cultural identity is the result of socialization which can be shaped by a number of external factors. As Aziz and Hasanali. (2000) explain, when discussing socialization in the context of traditional culture we recognize this process has both a teaching and learning component to it. For instance, certain behaviors can be taught to people at a very young age. Behaviors such as obeying authority, conforming to certain social roles, and the practice of certain rituals, and customs (Aziz et al. 2000,616). Behavior can also be steered by factors such as cultural traditions, religious obligations, family loyalties and commurity expectations (Hennink et al., 1999, 867). Thus, we can understand culture as being a social construct that involves both the transmission and adoption of behaviors, ideas and values among members of the same social group.

Historical Context: The Tibetan Refugee Diaspora

Perhaps the most striking characteristic of Tibetan communities outside of Tibet has been their ability to preserve and maintain a distinct cultural identity despite spending many years in exile. The failed uprising in Tibet in March 1959 that led to the flight of the Dalai Lama was indeed the catalyst which began the exodus from Tibet (Hess, 2006, 80). Since that time, there has been a steady 
stream of outward migration from the region. In a demographic survey conducted in June of 1998 by the Planning Council of the Central Tibetan Administration, it was estimated that the exile population had reached $122,078^{1}$ (Basu, 2009, 424). More recent figures have estimated the Tibetan exile community to be over 130,000 which represents a significant portion of Tibet's overall population (Hess, $2006,87)$. The majority of Tibetan re-settlement, and indeed the largest exile populations exist today in India and Nepal (1998, CTA Household Questionnaire as cited by Migration Information Source). However, Toronto is home to the second largest Tibetan population in North America after the New York/New Jersey area according to the Central Tibetan Administration (CTAC, 2002 as cited by Yeh \& Lama). And, according to the 2006 Census of Canada, which detailed the mother tongue of those living in the Metropolitan area of Toronto, 3,145 respondents indicated that Tibetan was either their sole language and or one of the multiple languages they spoke (Canadian Census, 2006) ${ }^{2}$. An even closer examination of the Tibetan population in the Toronto neighborhood of South Parkdale where this study took place, reveals that a total 1,735 respondents identified themselves as Tibetan, making them the fifth largest ethnic group in this area (City of Toronto, Social Profile \#2 - Neighborhoods,

\footnotetext{
1 The Central Tibetan Administration announced it would be carrying out a second Tibetan Demographic Survey in April 2009. This data was not publically available at the time of writing this paper.

${ }^{2}$ According to the Canadian Census, the category 'Total - Single and multiple language responses indicates the number of respondents who reported each language, either as their only response or in addition to one or more other languages. Total responses represent the sum of single language responses and multiple language responses received in the census.
} 
Language and Ethnicity for South Parkdale, 2006) ${ }^{3}$.

Tibetan refugee diasporas have been able to carry on a cultural legacy in exile despite physical detachment from and limited contact with their homeland and indeed the epicenter of their spiritual and cultural world. This can be explained in a number of ways. Of crucial importance is the role the Tibetan Government in Exile in particular has played in creating cultural and social cohesion among what might otherwise be a very disparate population.

Retaining and Sustaining a Cultural Legacy in Exile

When people flee from the threat of death and total dispossession, the things and stories they carry with them may be all that remains of their distinctive personhood to provide for future continuity (David Parkin as cited by Couldrey \& Morris, 1999, 4).

Since 1959, a major concern of the Dalai Lama, his Tibetan Government in Exile and indeed within the refugee diaspora at large has been the preservation of Tibetan culture. From the very onset of his life in exile, the Dalai Lama was quick to recognize that the aspiration of returning home to Tibet might not be immediately realized and that it was possible the Tibetan refugee diaspora may remain uprooted for an indefinite period of time (Harris, 1999, 13, Basu, $2009,419)$. Prompted by "the disappearance of Tibetan culture in the homeland under Chinese rule and the disappearance of exiled Tibetans in the host

\footnotetext{
${ }^{3}$ Ethnic Origin refers to the ethnic or cultural group(s) to which the respondent's ancestors self-identified. Source: Statistics Canada: 2006 Census
} 
societies" (Basu, 2009, 420) the Dalai Lama placed great emphasis on reconstructing the monastic institutions of Tibet in exile as a means to preserve cultural traditions and to educate Tibetan youth about Tibetan values (Harris, $1999,13)$.

Today, across the Tibetan exile world, physical evidence of these efforts can be seen in a number of ways. In refugee settlements in South Asia, the architectural design of houses and temples has been modeled in the image of those that might be found in the villages and cities of Tibet. The interior of homes belonging to Tibetan exiles, even those living in North America, might commonly display various traditional and religious Tibetan objects and artifacts. As Basu explains, all of these physical reminders serve an important role in what he describes as "place-making" which is intended to "re-establish continuity with the place of origin" (Basu, 2009, 440).

This type of continuity and cultural transrnission can take other forms including language, beliefs and even codes of conduct which are passed from older to younger generations. In particular, there exists a strong oral tradition among Tibetan refugee diaspora families and communities that involves "the telling and retelling of stories" from one generation to the next not only about Tibet but about the Tibetan struggle as well (Basu, 2009, 440).

\section{Cultural Ambassadors}

As the research suggests, within exile communities, younger generations are viewed as playing a particularly vital role in sustaining, preserving, and 
promoting Tibetan culture. As Phuntsog describes it, "they are the dreamkeepers of an independent Tibet nation." $(1998,36)$. As dream-keepers those living in exile serve as a type of cultural ambassador whose primary responsibility is to "raise the voice of Tibetan freedom and independence, be a force to make the [world] aware of what is happening to the Tibetan people in Tibet' and develop communities that represent authentic expression[s] of Tibetan Culture" (CTA, 1992, back cover as cited by Yeh \& Lama, 2004, 813). As we learn from the literature, playing the role of cultural ambassador can be fraught with challenges including inter-generational and inter-personal tensions especially to when it comes to the ways individuals behave and choose to represent their culture.

First however, it is crucial to understand that the role of cultural ambassador is not simply something that is imposed. Indeed there can be a great willingness and enthusiasm on the part of younger generations to voluntarily carry this torch of cultural preservation on behalf of their community. As the literature tells us, rather than being passive followers many younger generations studied exhibit a great deal of agency when it comes to cultural maintenance and preservation. For second or third generations of Tibetans born outside of Tibet, limited contact with their ancestral home has not deterred many from taking an active interest and or involvement in their local Tibetan community or in the wider Tibetan political movement. As Hess (2006) explains, the dream of one day returning to Tibet still very much resonates with a large number of people, and that for "those in their twenties and thirties, and born in exile, "return" 
to Tibet is as much a part of an imagined future as it is for their parents" (2006, 93). Such strong identifications and allegiances to Tibet are both significant and revealing in that they help to shed light on the ways in which younger generations of Tibetans in exile acculturate when settling in a new country.

\section{Existing Research on Strategies of Acculturation for Tibetans in Exile}

It is difficult to assess from the literature on Tibetans in exile whether one of Berry's strategies of acculturation is more prevalent than others. Indeed, examples of integration, assimilation and even separation can all be found in the body of literature. This is in large part due to the fact that most of the studies examining Tibetan exile life take place in very unique and sometimes drastically different settings and countries.

Since acculturation often takes place in culturally plural settings, researchers have found it is common for second and third generations migrants to have identities which represent a fusion of their native culture and that of the country they now inhabit. A person may describe themselves as having a hybrid or hyphenated identity which reflects this type of cultural co-mingling. Some research has indicated that younger generations in particular desire to retain "some core heritage, some amalgam of family cohesion, religion and language, probably in an adapted form, but did not expect this to mean segregated social lives" (Robinson, 2009, 450).

If we examine the literature on Tibetan second and third generations, we see examples of young people living ethnically-plural lives. For instance, Yeh and 
Lama (2004) in their study of Tibetan youth living in Boulder, Colorado and San Francisco looked at the ways hybrid-identities were expressed. These authors found examples of young exiles gravitating and adopting elements of American hip-hop culture and fusing it with their own Tibetan cultural heritage. The authors observed that many young Tibetans exhibited aspects of this sub-cultural genre in the clothes they wore, the music they listened to, the social activities they engaged in and even in their mannerisms and ways of speaking (Yeh \& Lama, $2004,822)$. The authors observed that hip hop culture and rap music specifically were attractive to many youth, particularly when it embodied themes of resistance, anti-oppression and anti-racism. It gave younger Tibetans, "a sense of active engagement in popular culture, projecting an image that is stylish, modern, associated with freedom, and definitely not white" (Yeh \& Lama, 2004, 824). As Yeh and Lama discovered, hip hop also helped individuals cope with the realities of living as refugees in forced exile as well as the discrimination they might encounter as racial minorities in America. Hip Hop also provided youth with an outlet through which they could express and promote their Tibetan identity and the collective Tibetan struggle as indicated in this quote from one study participant, who suggested,

Maybe after 3 to 4 years we might have Tibetan rappers who will spread awareness among people [about Tibetan independence] and we will make many fans. Then we might win Tibet back with their support. (Yeh \& Lama, 2004, 824). 
In fact, Yeh \& Lama found numerous references to Tibet, Tibetan oppression under Chinese rule and Buddhism in the lyrics of rap songs young Tibetans would write $(2004,823)$. What is evident in the research of these authors, is that above all, young Tibetans with this type of hybrid-identity saw hip-hop as being completely compatible with their Tibetan culture and they always maintained a deep connection to their Tibetan roots (Yeh \& Lama, 2004, 824). Similarly, Diehl (2002) in her study of Tibetan musicians living in exile in India, found the adoption of specific musical genres, in this case, Rock and Roll, provided a powerful cultural channel for Tibetan exiles to express themselves, their Tibetanness and their ideas. As Diehl points out:

As a style and as an ideology, Western rock-and-roll music is a powerful resource for young Tibetan refugees trying to imagine and pursue personal and political rangzen (independence) and seeking ways of being "modern" without deviating from the conservative core values of their community. $(2002,30)$.

Phuntsog (1998) suggests that Tibetan exiles are more likely to adopt an integrative approach of acculturation as evidenced in the research by Diehl, Yeh and Lama. He explains that although Tibetan communities in exile are "zealous" in their efforts to find ways to maintain their cultural and ancestral heritage, at the same time they eagerly adopt a lifestyle to meet the "the demands of the modern world" (Phuntsog, 1998, 37). This is supported by Basu who describes Tibetan refugees, at least in India, as constituting "a good model of integration with their host populations" $(2009,420)$. As these authors would argue, although cultural 
maintenance has become a priority for many Tibetan refugees, it has not constrained or discouraged them from adapting or engaging with their new surroundings.

However, some researchers present a more contrarian view, suggesting that a number of Tibetans in exile, even younger generations, associate cultural hybridity as being tantamount to Tibetan cultural erosion. At issue are the ways Tibetanness, which Anand (2000) describes as being a narrative of national identity, is seen as being at odds with other cultural traditions. For example, Falcone and Wangchuk have commented on Diehl's findings suggesting that although it appears her informants' culture was being reconstituted in exile, "in the end she rejects the notion of hybridity, because her informants see such adaptation as the very unfortunate consequences of refugee life, as embarrassing failures rather than sources of pride" $(2008,188)$. Falcone and Wangchuk's observation is that rather than an authentic embrace of multiple cultural identities, cultural hybridity is more of a veneer among some Tibetan exiles. This is something they discovered in their own research of Tibetan exiles in India. Rather than inhabiting a "third-space" of hybridity as these authors describe it, their participants gravitated to and felt ultimately more comfortable within their own Tibetan culture. They found, "a good deal of acceptance and tolerance of certain adopted "Indian" customs and aesthetics by Tibetans in exile (affection for cricket, Bollywood, curries, etcetera)...but since "Tibetanness" is often enforced with vigor sometimes bordering on brutality, the "third space" remains a controversial and tension-inducing space" (Falcone \& Wangchuk, 
$2008,187)$. Thus as they argue, "By and large Tibetans in exile have not embraced "creole culture," and although they may in fact embody it, many struggle fiercely to resist it" (Falcone and Wangchuk, 2008, 188). These authors suggest their informants carefully tread the divide between Tibetan and nonTibetan worlds.

Although not fully dismissing the thesis that Tibetan exiles adopt an integrative approach to acculturation as put forward by Yeh and Lama (2004), Phuntsog (1998) and Basu (2009), Falcone and Wangchuk (2008) raise the prospect that it is possible individuals will adopt an integration strategy that involves elements of both integration and separation. They also suggest the acculturation experience during settlement is a process often rife with tension. Acculturation, they argue, for a younger generation Tibetan exile, involves trying to make sense of competing notions of identity, clashing cultures and the expectations of others.

Houston and Wright pick up on this theme in their research, which examines the relationship between the individual and the larger Tibetan community and the ways this relationship influences acculturation. They recognize Tibetan culture as being a collectivist culture meaning that it stresses "we consciousness, collective identity, group solidarity and duty" (Kim et al. 1994 as cited by Klassen, 2004, 732). They describe the collectivist identity of Tibetans as a type of "Grand Narrative of Tibetan Nationalism" and that against the backdrop of this narrative their study participants in Kathmandu, McLeod Ganj, and Boston regardless of gender, class and age difference often "rehearsed the 
rhetoric of a singular Tibetan identity, comprised of language, religion and cultural expressions" (Houston \& Wright, 2003, 222). Yet this emphasis on cultural cohesion, as well as maintaining a singular, consistent Tibetan identity had consequences for many of Houston and Wright's (2003) participants. Those individuals who pursued alternative forms of expression or identity were greatly discouraged from doing so. This phenomenon which Hennink et. al. described as "associated behavioral expectations" refers to both the perceived and real expectations that a young person feels from family, relatives and or their community $(1999,870)$. In the case of Tibetan youth, many sensed adopting too many "non-Tibetan" customs, mannerisms and characteristics would be construed by some in their community as being a threat to Tibetan cultural preservation efforts. Some of Houston and Wright's (2003) informants reported that if they were seen to be transgressing the boundaries of traditionally held cultural norms, they were kept in-check by other members of their immediate community through subtle gestures, comments and even glances, as evidenced in this quote from a woman named Dolma whom they interviewed: "[i]f I try to be too hip or vogue people say 'Uh-uh, you're a Tibetan, try to remember that.' It's a constant reminder to me." $(2003,224)$. Likewise, Yeh and Lama found their young Tibetan informants in America who adopted elements of hip-hop culture were often at odds with elders and community leaders, "who conflated hip-hop not only with delinquency and encounters with legal authorities, but also with an "embarrassing imitation of blacks" $(2004,824)$. Thus, for some, hip hop came to represent the antithesis of Tibetan culture and embracing it was considered an 
insulting rejection of Tibetanness. Thus, as this literature reveals younger generations often confront pressure from elders and others in their community to adopt a limited integration strategy. Anand provides an explanation for this when he suggests this phenomenon as being a reflection of the Tibetan Government in Exile's policy which encourages a policy of "limited acculturation as opposed to assimilation" for its exile population $(2000,275)$.

As this research has pointed out, cultural identity can survive but can also transform in exile. As Frank Korom's (1999) research of Tibetan children in Switzerland demonstrates, it is also possible for Tibetan individuals living in exile to adopt an assimilation strategy of acculturation. At the time of writing his paper, Switzerland was host to the greatest number of Tibetans in exile in all of Europe (Korom, 1999, 3.) He suggests, a real loss of Tibetan culture and religion took place for an entire generation of Tibetan orphans or "unaccompanied children" who were placed in Kinderforf (children's village) or Swiss foster care (Korom, $1999,5)$. With limited access to a greater cultural community, Korom notes that many of the Tibetan orphans grew into adults detached from their ancestral heritage, with very little, limited or no knowledge of Tibet or Tibetan culture. Over time he suggests, they developed a type of "cultural amnesia" (Korom, 1999, 5) from a lack of exposure to their Tibetan roots. Further exacerbating the situation was the pressure his informants felt to culturally assimilate into Swiss society. As he concluded, "at the same time that Tibetans wish to regulate identity in exile communities, the pressure to adapt and assimilate to the host culture has led to the external appearance of extreme acculturation" (Korom, 1999, 8). 


\section{Citizenship}

It becomes clear when reading the literature that there are a number of ways in which an individual can acculturate into a new society. The integration process might involve changes in behavior, dress, habits, mannerisms and attitudes. It can also involve a very concrete and formal procedure such as the adoption of citizenship. Yet, in the literature on Tibetan exiles, citizenship has been and remains to be a highly contentious subject within the Tibetan diaspora (Basu, 2009, 433). It is a complicated notion in which issues of nationality, cultural identity, political allegiance and symbolism converge and sometimes clash. For many exiled Tibetans, adopting the citizenship of a country outside of Tibet may be perceived as being counter to the goals of the Tibetan struggle for independence and to a certain extent, is viewed as being a declaration that a person has abandoned the hope that Tibet will eventually be free (Hess, 2006, 84). Denying citizenship, can thus be a highly symbolic act, a powerful form of patriotism and a gesture of absolute commitment and allegiance to Tibet (Anand, $2000,275)$. It can also serve as a way to show solidarity with fellow Tibetan refugees worldwide (Basu, 2009, 439). For these reasons, a number of exiled Tibetans refrain from becoming citizens of the countries they settle in or in some cases have lived in for generations. The most notable example of this is in India where Hess suggests despite the insecurity associated with statelessness, the vast majority of Tibetans choose not to become Indian citizens despite being eligible to do so (Hess, 2006, 84). 
It is however, vital to recognize a contradiction in the literature on this issue. For while Hess (2006) argues citizenship is readily available to Tibetan residents of India, Falcone and Wangchuk point out that "in practice Tibetans in exile, including the second and third generation, are routinely refused [citizenship]" $(2008,168)$. Therefore it becomes crucial to take into account the bureaucratic processes which can also play a role in citizenship matters. It may even be possible that difficulties obtaining citizenship in India have prompted and/or partly encouraged younger Tibetans, specifically professionals and those with advanced education to leave and migrate to countries such as Canada and the United States where citizenship is seen to be more easily attainable.

In the context of identity construction, particularly for second and third generation Tibetans, we can see the ways in which the issue of citizenship takes on new dimensions particularly in terms of settlement and acculturation. Hess points out that younger generations of Tibetans in exile are constantly articulating and consciously negotiating multiple loyalties $(2006,91)$. It is a fine balancing act in which individuals constantly and carefully weigh the pros with the cons of the citizenship issue. Although there remains a sense of anxiety that adopting the citizenship of another country may lead to a widening of the gap between younger generations of Tibetans and their ancestral home, this is being offset with the potential benefits which citizenship, particularly in Western nations, might offer. Younger generations of Tibetans in particular are seen to take a very pragmatic approach to the citizenship issue. Instead of being a sign of splintered loyalty, many view citizenship as a tool which aides in the acculturation and 
settlement process. It becomes a strategy "designed to maximize social and economic capital and a means to enhance a collective sense of security" (Um, $2006,10)$. As citizens, Tibetans can use their status as a means to "strengthen ties with the Tibetan diaspora, and with family that remains in Tibet as well as to marshal resources that increase the effectiveness of the transnational Tibet movement" (Hess, 2006, 92). Perhaps one of the greatest motivating factors encouraging younger Tibetans to adopt citizenship is that is opens up the possibility they may one day have the ability to return to Tibet, something which as stateless individuals, they could never achieve otherwise (Hess, 2006, 92). Indeed, the Tibetan government in exile has recognized the potential citizenship brings with it, and has gone so far as to allow in its Charter for the possibility of those in exile to enjoy dual citizenship (Hess, 2006, 84).

What this literature reveals is that citizenship can be part of the integration process. It also suggests that citizenship allows for individuals to maintain and even foster new ties with Tibet. It is possible, particularly for younger generations of Tibetans to identify with multiple attachments and multiple places at one time (Basu, 2009, 433). Although obtaining citizenship is no guarantor of equality in a new society, it can create possibilities for individuals to preserve their cultural identity in new ways. Migrating to the West in particular with the eventual aim of obtaining citizenship is less a symbolic gesture than it is a practical one because it is seen as a strategic way for some young Tibetans to realize their dreams of economic advancement, and advance their collective political agenda (Hess, $2006,88)$. 
Tlbetan Identity and "Tibetanness"

Internal Concepts

As much of the literature on Tibetans in exiles has revealed, maintaining a distinct cultural identity remains a priority for individuals even during the settlement and resettlement process. Cultural preservation may be even more of a priority for Tibetans than for other migrant cultural groups in Canada, given that the nature of the political situation in Tibet has greatly hindered and in some cases outright severed transnational ties between this exile community and their country of origin. Thus, a vigorous attempt to protect cultural identity, as

Phuntsok describes it, may be one of the best ways in which younger generations can connect with a place they have increasingly tenuous links with.

On the surface it may also seem perplexing why younger generations of Tibetans are so driven to return to Tibet, even without ever having been there before.

According to Um (2006) this strong desire and nostalgia is explained in this way:

It is the search for identity, through the reclaiming of a denied past, that compels the return. It is a way of connecting with their families, by sharing in the trauma that casts a pall even over those who did not live through those defining historical events $(2006,18)$.

Thus, in searching for this identity, this past and this culture, younger generations are ever conscious of the need to uphold their positions as "cultural ambassadors" of Tibet, even as they struggle with the challenges associated with settling in a culturally foreign landscape. 
Yet this identity of cultural ambassadors is complex and contradictory. Unpacking the notion of cultural identity reveals how problematic a concept culture actually is. It raises the question as to whether culture is only articulated through language, a belief system, ways of behaving or dressing. It assumes Tibetan culture is something tangible, fixed and easily defined and that distinctions can be drawn between what is authentic Tibetan identity and what isn't.

As Anand explains, it is impossible to map and reconstruct cultural identity because identities are by nature fragmented, fractured, never singular but rather, "multiply constructed across different, often intersecting and antagonistic, discourses, practices and positions" $(2000,273)$. As some of the authors indicate, younger generations in exile are most likely to confront these questions as they try to navigate the settlement experience. As Falcone and Wangchuk have observed, second and third generation Tibetans born in India, are often "the most perplexed about the contours of their national identity" $(2008,187)$. This quandary is the focus of much of the literature in this area.

A term that emerges in the literature investigating acculturation among second and third generation immigrants more generally, is associated behavioral expectations. Hennink et al. describes this as the perceived and real expectations that a young person feels from family, relatives and or community $(1999,870)$. Immigrant youth in particular often feel torn between meeting their parents' expectations and fitting in with peers (Tyyskä, 2003b, 2006 as cited by Tyyskä, 2007, 89). There can also be a gendered dimension to expectations. 
Often young women experience greater scrutiny of their behavior and greater parental expectations than males. For instance, females in many ways come to represent the "cultural vessels" in many immigrant communities and as a consequence, their behavior is seen to be a reflection on their family and the larger immigrant community (Tyyskä, 2007, 90).

\section{Western ideals of Tibetanness}

Several authors suggest that beyond encountering familial and community expectations, Tibetan migrants in particular encounter an additional layer of expectations from their receiving societies as well. Authors such as Yeh and Lama (2004), Lopez (1999), Adams (1996) and Diehl (2002) have all acknowledged that Western constructs of Tibetanness add yet another complex dimension to the settlement experience for Tibetans. Yeh and Lama note that their informants in Boulder, Colorado and San Francisco often had to respond to the "romantic image of Tibetans in the Western popular imagination" $(2004,811$. Lopez argues that in the popular imagination, Tibetans are generally idealized as being content, enlightened and spiritual people $(1999,10)$ and these expectations, perceptions and stereotypes often greet Tibetan newcomers in their various encounters and exchanges with people in the receiving country.

As some authors have argued, these exoticized and essentialized Western constucts of Tibet and Tibetans have managed to permeate popular culture, media and indeed have become part of an over-arching Tibetan 
Nationalism. As Harris points out, "An exilic elite of religious figures and artists, writers, performers and musicians has been at the forefront of the promotion of what is in fact an invented tradition of what it means to be Tibetan after 1959" $(1999,14)$. The invented traits, features and characteristics described here can also ultimately become a type of prototype cultural identity, which is an idealized notion that may be more imagined than real. The result is that this romanticization and orientalization has in many ways essentialized Tibetans (Meredith, 2002, 105). Yet Lopez suggests this image of peacefulness, tranquility and deep spirituality, is sometimes appropriated and used by exiles as a means to gain better standing in the receiving country and to garner support for the independence movement $(1999,10)$. Clifford on the contrary, puts forth the argument that individuals are willing to adopt these exilic notions of Tibet and Tibetan culture because it aids them in the settlement process by providing them with a sense of hope, and optimism while they deal with the brute facts of surviving in "host countries" (Clifford, 1994 as cited by Harris, 1999, 14). Yet ultimately, such an idealized notion of Tibetanness has a flattening effect in that it can deny alternative expressions. Houston and Wright observed among their informants that regardless of gender, class or age difference people often "rehearsed the rhetoric of a singular Tibetan identity" (Houston \& Wright, 2003, 222).

What this research on Tibetan identity reveals is that Tibetans in exile may be subject to a variety of cultural expectations from their families, communities, and the wider society in the receiving country. It is also apparent that the 
imagined and contested construct of Tibetanness has an effect on those who consider themselves Tibetans. (Anand, 2000, 272). Such idealized concepts of cultural identity suggest that Tibetanness is concrete, unchanging, pure and infallible (Falcone \& Wangchuk, 2008, 190). This can become problematic when younger generations of Tibetans face pressure to live up to these often unrealistic standards of behavior. In reality, identities are constantly in flux, and subject to multiple influences and interpretations (Tyyskä, 2007, 92). They are not stuck in an eternally fixed past but are rather subject to history, culture and power relations (Anand, 2000, 278).

Cultural identities are complex. They do not remain static but rather fluctuate and transform during the settlement process. It is important to keep in mind that identity formation is also a complex issue, more so for ethnic minorities who often must confront and reconcile between the expectations and values of their own culture and that of the receiving society (Graf et al. 2008, 59). While younger generations may accept and conform to some of their own group's cultural norms and values, they might also develop attitudes and opinions that will greatly vary.

\section{Obstacles in the Settlement Process}

It becomes apparent that Tibetans moving through the settlement process, like other migrant counterparts, experience a host of challenges. The literature thus far has explored the cultural challenges individuals can often encounter. In addition to this, individuals confront a bevy of additional obstacles including 
barriers to employment, and discrimination which can make the settlement experience particularly challenging. How individuals deal with and attempt to overcome these obstacles is very relevant because factors such as cultural cohesion, cultural values and one's sense of identity can all play a part in assisting and supporting individuals moving through these processes. Indeed, the ability for Tibetans to seek comfort in their belief system, values and traditions, as well as their cultural community can all strengthen the resilience of individuals. This resilience in turn "allows them to grow and adapt to their new surroundings and develop the skills to respond to challenges they encounter" (Boyd, 2006, 86).

There exists a scant amount of literature examining the specific settlement experiences of Tibetan refugees in Canada. There is however, a vast amount of research examining the settlement obstacles racialized or ethnic minority migrants are likely to encounter upon arrival in Canada. This research suggests that settlement poses greater challenges for racialized groups than for nonracialized groups. In general, ethnic minorities upon landing in Canada are more likely to suffer from structural conditions and this can often set them on a course of menial employment, poverty, and struggle (Tyyskä, 2007, 93). There is a general understanding that racialized migrants are more likely to have their foreign credentials and education either undervalued or outright rejected by established Canadian companies, hiring organizations and professional bodies. They also may encounter language barriers which may hinder their ability to access social and governmental services and gain meaningful employment in 
their field of expertise (Ferrer \& Riddell, 2008, 187).

All of these factors greatly influence the settlement experience in Canada. Refugees in particular are likely to face a tremendous amount of discrimination. As a consequence, individuals are denied a sense of belonging in the receiving country which hinders their adaptation and settlement (Um, 2006, 10). Further constraining refugees are the bureaucratic processes related to family reunification. As Rousseau et al. (2003) argue, "refugees flee their homeland in a hurry, and leave some or all of their loved ones behind and seldom are their reunification goals immediately realized $(2003,1095)$. Ultimately, one barrier compounds another. Coping with discrimmination, having one's credentials denied, and struggling to reunite with loved ones can make the acculturation process extremely challenging and stressful for an individual. Rather than experiencing success during settlement, individuals may feel defeated. As Um suggests, this "prevailing sense of marginalization and insecurity in diaspora amplifies the siren call of the homeland" (Um, 2006, 10).

However, the cultural ties and values of a migrant can in many ways help alleviate if not positively offset these negative conditions. For instance, participation in a community program, a religious or a cultural centre can provide a refugee with a sense of belonging and support. Not only can it assist an individual who is attempting to make sense of the settlement process, it can also assist those coping with the reality of displacement. As Clifford (1994) has observed, "participation in community programs thus enables diasporas to live out the tension embedded in the 'experiences of separation and entanglement,' 
of living here and remember/desiring another place" (Clifford, 1994, 15 as cited by Um, 2006, 11). Shared cultural bonds between migrants can create tremendous kinship networks which in turn provides them with the much needed social capital they require to adapt and cope with the challenges posed during settlement (Lewis-Watts, 2006, 84). It becomes apparent that maintaining one's cultural identity and feeling a sense of membership to a larger cultural community can not only be very meaningful for an individual, it can be of great importance as they navigate the complex web of settlement.

Implications for My Research

The literature review sensitized me as the researcher to a number of important themes that arose when other researchers had studied Tibetan exiles and the settlement context. One of the shortcomings identified in the literature reviewed is that although terms such as "Tibetanness" and Tibetan identity are frequently used by researchers, there is no definitive understanding of what these terms mean. These authors each in their own way, have attempted to explore what Tibetanness means, to the individual, to the collective and even to the outside world. As the literature suggests, perceived authentic Tibetan identity is often narrowly defined and represents a particular set of values, and sometimes a specific code of conduct. The research also suggests by and large that Tibetan refugees have a tendency to conform to a particular interpretation of Tibetanness or Tibetan identity which leaves little room for deviation and which is stringently upheld by cultural institutions and or elder community members. As the authors 
cited here point out, this concept of Tibetan identity is a fixed one and might not reflect the real experiences and transformations of self that can take place during the settlement process. It is important to recognize that if subscribing to a particular and narrow definition of Tibetanness or Tibetan cultural identity, there is a risk of upholding the very notions researchers are supposed to critically examine. Therefore, it is important to be selective and attempt to use definitions of Tibetan culture and Tibetanness that are broader and more encompassing. For the purpose of this exploration, the term Tibetan will refer to those individuals with ancestral ties and/or a cultural heritage that can be traced to Tibet. By extension Tibetan cultural identity and Tibetanness will encompass the various practices, values, traditions and expressions as articulated by Tibetan people. This review of the literature also confirms the need for a study such as this that specifically examines issues of identity for Tibetan refugees moving through the settlement process in Canada and more specifically the Tibetan refugee population in Toronto. As previously mentioned, Toronto is home to the second largest Tibetan population in North America yet despite their relatively sizable population, there has been little research published on Tibetan refugees in Canada, let alone research specifically looking at the experiences of younger generations of refugees.

Finally, several authors reviewed suggest that if Tibetan refugees in exile are settling in a new environment, then they are likely to adopt a version of Berry's integration strategy which can allow for limited acculturation because upholding and keeping their original cultural identity intact is of utmost importance. The 
findings of the literature reviewed suggests the settlement experience for Tibetans in exile is often marked by tension as they attempt to acculturate to a new climate and at the same time keep a distinct cultural identity intact. As the literature on Tibetan exiles suggest, there are a number of acculturation strategies individuals can adopt during the settlement process. In exploring the historical and cultural context of the Tibetan diaspora it becomes apparent in previous research that acculturation strategies are shaped and influenced by culture, cultural expectations and even systemic barriers in the receiving country. It is also evident how younger generations can adapt and even renovate their culture as they move through settlement. Ultimately, preserving one's cultural identity is a value that continues to resonate with younger generations in exile, and this is reflected in the ways they choose to navigate the settlement experience. Thus, researchers investigating the settlement experience of Tibetan refugees in their 20 s and 30 s in a Canadian context must consider the role and influence culture and cultural identity can play.

\section{Chapter 3: Methodology and Research Design}

This project will attempt to address some of the gaps in the current literature created by the lack of research on the Tibetan Diaspora in Canada. What is needed is research that either confirms or challenges the findings derived from research in other countries as it applies to younger generations of Tibetan refugees in Canada. Another area that needed further exploring was whether these efforts to preserve cultural identity serve to undermine or hinder 
the successful settlement experience of individuals, or if they assist in the acculturation process. Such insights are of great importance particularly in a city such as Toronto where there is a large Tibetan refugee population. Ultimately, all of these issues outlined above inform my interview questions. However as a qualitative researcher, I will also examine what other themes may emerge during discussions with study participants.

\section{Research Design}

The methodological technique adopted to gather data in this study was in-depth, open-ended interviews. This was an approach also adopted by Yeh and Lama (2006) and proved very useful in obtaining highly detailed, first-person descriptions, accounts and testimonials that ultimately painted a highly vivid portrait of the participants' experiences as they adjusted to life in a new land. The open-ended interview technique also allowed participants to share their feelings and reflections over identity issues. This proved a very useful strategy in that it allowed me as the researcher to draw out and identify key concerns as well as get a sense of the diversity of experiences among participants. This was essential in this exploration of how Tibetan refugees make sense of their cultural identity during the acculturation process. There were five study participants in my sample and these included both women and men of self-identified Tibetan origin who have come to Toronto in the last four years as refugee claimants. 
This study uses a naturalist paradigm as well as the acculturation framework developed by Berry (2007). In this case, the data which informants provided about their understanding of Tibetan identity and settlement in Canada provided insight into the acculturation strategies they were adopting which in turn allowed me as the researcher to test the hypothesis. In addition to this, the naturalist framework allowed me to be an instrument within the inquiry process. Through questioning and interacting with study participants, I could develop a "holistic and thick understanding of a particular phenomenon" (Westhues, et al., $1999,136)$. The different ways in which study participants interpreted what was happening to their own Tibetan cultural identity as they moved through settlement provided a broader portrait of the various acculturation processes they were adopting.

Many of the researchers who conducted in depth studies of Tibetan exiles settling abroad chose a qualitative research method as their inquiry process. A qualitative approach was also selected for this study because it serves as a means to explore and understand the meaning that "individuals or groups ascribe to a social or human problem" (Creswell, 2009, 4). A qualitative approach was also used for this study since I as the researcher would analyze data from specific to more general themes and then ultimately interpret that data (Creswell, 2009, 4).

\section{Ethical Considerations}

Before proceeding with participant selection, it was imperative for me as 
the researcher to be sensitive to the fact that there might be a reluctance on the part of some individuals to speak candidly on record, especially if they felt their remarks might be interpreted as being overly critical of elders, family members, and or community leaders. It was important for me to reassure participants that the study would be conducted in a respectful way and that their identities and or the identities of individuals they mentioned would be kept confidential. To ensure participants understood the confidential nature of the study, I explained and walked participants through the consent form and answered any questions that arose. It was also important to be cautious of the fact that the nature of the discussion had the potential to be difficult if it dealt with traumatic events which may have occurred prior to migration. It was important I assure participants that at any point during the interview, should they feel uncomfortable with the subject of questioning, they were free to stop the interview momentarily and or withdraw from the study all together. Despite the risk for discomfort and emotional stress, the participants seemed relaxed and very much at ease during the interview sessions.

Perhaps one of the biggest obstacles on data gathering was the real possibility that participants might be too preoccupied with resolving the day to day challenges involved in the actual settlement process to discuss issues of identity. It was important to respect and acknowledge the life priorities of study participants and thus allow for some room in the interviews for individuals to discuss matters of great importance to them including issues regarding the refugee application process, accessing certain social services, and or familial 
concerns. As the researcher, it was important I be open to the possibility of assisting participants address these concerns so long as it could be done without compromising objectivity. Ultimately, by not limiting discussions to a fixed set of questions, individuals had the flexibility to share their concerns as well as stories, and other details of their settlement experience which served to enhance the research and findings.

\section{Participant Selection}

Participants for this study were recruited through the process of snowball sampling which involves finding a research sample within an existing network, a network in which each person is connected with another through either direct or indirect linkages (Neuman, 2006). Key informants were first identified using existing connections which I, the researcher had developed during a Graduate Student Placement at the Kababayan Community Centre in Parkdale, Toronto in 2009. This centre, which receives funding from three levels of government (municipal, provincial and federal) provides a host of settlement services for newcomers, immigrants, refugees and foreign temporary workers. It is located in the heart of Parkdale, Toronto and thus an agency frequently accessed by Tibetan refugees living in the surrounding area. Utilizing contacts that had been maintained with fellow volunteers (all Tibetan) I was able to find potential study participants. The existing relationship which I had with some of the study participants proved very useful because study volunteers felt comfortable sharing their stories and experiences with me. This also proved useful when it came to 
recruiting other would-be participants because individuals felt at ease knowing that $\mathrm{I}$, the researcher, was a familiar acquaintance of a friend of theirs.

In two cases, I contacted key informants first, and requested they inform friends, family members and colleagues about the study. In three instances, I approached existing contacts directly and informed them about the study. In all cases, individuals were supplied an information sheet detailing the nature of the research. A variety of Tibetan men and women were contacted. Individuals who were interested in participating were given my contact information including telephone number and email address. Correspondence between myself and any interested individuals followed and was conducted by email and by phone. These initial conversations provided a time for an informal discussion about the various aspects of the study. Once a participant confirmed their participation, an interview session was arranged.

A preliminary analysis of the existing literature was conducted where key themes, concepts and ideas were extrapolated and compiled into an interview guide which was later presented and used in interviews with participants. Participants were required to take part in a one hour (maximum) in-depth interview with myself and complete a consent form. Interview sessions took place at times that were convenient for the participant, either after or before work and or on weekends. Interviews also took place in convenient settings, either the participant's home, a private room in the Parkdale Library, or another private setting within walking distance of their residence. All interviews were recorded using a digital recording device and were later transcribed. Participants were 
required to supply written consent granting permission for their conversations to be recorded. A total of five participants signed up for and attended interviews. This number of perspectives although limited, allowed for more in-depth discussions with individuals about their unique experiences during settlement. The discussion in these interviews allowed for a review of the themes raised in the literature review, and a further discussion about the particular settlement experiences of participants. Additional insights related to issues about the nature of cultural identity as it relates to settlement were also uncovered. Although it was difficult to make generalizations about the findings given the sample size, this exploratory study succeeded in addressing some of the gaps in the research, thus paving the way for further study.

\section{Participant Demographics}

The sample for this study consisted of five participants, two women and three men. It was a diverse group consisting of individuals who had either been born in Tibet, India or Nepal and who had lived in one or more countries prior to arriving in Canada. Participants included individuals whose parents were first or second generation Tibetan exiles. Some of the participants' families had fled Tibet shortly after the exodus of the Dalai Lama. One participant was the first in her family to live outside of Tibet. All participants had migrated to Canada in the last four years and their ages ranged from $25-40$ years old. Four of the participants had completed high school and had attained post-secondary education. One of the participants had previously been a monk and his entire 
education and religious training was received in a Buddhist monastery in India. Prior to migration, two participants had careers and the rest had been students. One of the five participants had experience working full-time in Canada.

The familial composition of the participants also greatly varied. Two of the participants were married and three were single. One female participant's husband and two children resided in India while the other had migrated with his wife, but his two children were in the care of his parents in Nepal. Both of these participants had hoped to one day.sponsor and or reunite with their loved ones in Canada.

The migratory path of the participants also greatly differed and in some cases involved two or more countries. Three of the participants had lived and either worked or studied in the U.S. prior to arriving in Canada. One study participant had previously lived and studied in Nepal and India and had pursued law studies in Britain before moving to Canada. One participant moved directly from India to Canada. Four of the study participants had been in Canada between 3-4 years, one had been in Canada for a year and a half.

\section{Chapter 4: Results and Analysis}

The conversations with the five participants produced a wealth of data which could be identified and categorized into several different research themes. Some of these research themes were similar to those found in the literature review such as: expectations of cultural ambassadorship, issues of citizenship, cultural expectations and acculturation strategies. There were some research themes which were not mentioned in the literature, but did however emerge in 
the data of this particular study. Some of these different themes include: push and pull factors that influence strategies of acculturation, familial separation and feelings of displacement, lack of credential recognition as a barrier to settlement, and social support systems. The following findings were extrapolated from recorded discussions and provide useful insight into the experiences of the participants.

\section{Expectations of Cultural Ambassadorship}

During the interview sessions, participants expressed a great willingness to share their life stories and experiences as refugees. Discussions began with participants describing their attachments to Tibet. Most participants described feeling a very close connection with Tibet, and said that Tibet was a place they intimately cherished:

Tashi ${ }^{4}$ : I feel so much connected to Tibet. Whatever happens in Tibet touches me to the depth of my heart. It saddens me you know, if something bad happens in Tibet. I feel that it hurts me so much.

Karma: I have a very strong connection. I feel a very strong connection because my parents are from there, and I have roots there. If I was born in Canada or in America, I think I will not be as bound as I am now. So I think that's the difference.

\footnotetext{
${ }^{4}$ To protect the confidentiality of research participants, their names have been withheld in this study. Pseudonyms have been used in substitute of participants' real names.
} 
Nearly all the participants, with the exception of one, were the first generation in their families to have been born outside of Tibet. Even without ever having been there, most participants said they were quite familiar with Tibet and the conditions Tibetans were living under. This participant credited that understanding to transnational linkages he was able to develop through the use of technology:

Lobsang: My parents, they fled Tibet so they are the first generation. We've never been to Tibet to be honest. I've never seen Tibet and the Tibetan way of living inside of Tibet. It's just that, most of the time I watch the movies and through that medium I came to learn about Tibet. What Lhasa is and the relations between Tibetans and the Chinese which occupy inside Tibet."

Most participants credited cultural institutions, Tibetan schools and the efforts of family members for ultimately transmitting knowledge about Tibet and Tibetan culture to them. Often, it was the institutions that operated in exile, which they encountered in countries such as India and Nepal that served as cultural incubators where they learned about Tibetan language, traditions and Buddhist beliefs. Even the sole participant who had been born and had lived for several years in Tibet acknowledged that much of her understanding about the culture was received outside rather than inside Tibet:

Tsering: In Tibet I was confused. I didn't know what my identity was, all I knew was that I was Tibetan. And I wore a red tie every morning and would say Mao is my leader, Mao is a great leader. Even when I was in school I would study about the great leaders, the sacrifices they have made and how great our country China the motherland was. So for me, being Tibetan 
had not played that important a role. It wasn't like, (enthusiastically) 'Oh I am a Tibetan!' it was more like (non-challantly) 'Oh I am a Tibetan.' But then I went to India and discovered we are refugees, we are living in exile, [it] made me realize my responsibilities and goals and mostly my responsibilities towards my parents, towards my country, towards myself.

Allegiance and loyalty to Tibet was a common theme among the participants. In several instances participants discussed the notion of being "cultural ambassadors" of Tibet. The measures individuals took to preserve and promote their culture varied, but it often took the form of political engagement and raising awareness about the plight of Tibetan people:

Karma: Whenever I get a chance to talk to people I will talk about Tibetan culture. And I will participate in political activities like protesting.

Tsering: Whenever somebody asks me, I always make a point of making an extra effort to explain to them what Tibet is all about, what our situation is, whatever little I know.

Participants acknowledged their political engagement was motivated in part by a sense of obligation to the larger Tibetan exile diaspora. Though, they did not view their role as cultural ambassadors as something burdensome but rather as something that was personally fulfilling and meaningful:

Tashi: I still feel like I have to contribute to my community. That's why, even when things are really stressful, taking up this kind of job [volunteering with a Tibetan Youth Organization], still I am contributing something to my community. So even if I am not getting any salary for that, I get satisfaction for doing something. 


\section{Citizenship}

Related to the theme of activism and political engagement, participants were asked to share their attitudes over the issue of citizenship. All of the participants were stateless in the sense that they had not become citizens of any of the previous countries they had inhabited. Most of the participants described feeling a sense of precariousness and a sense of frustration because they lived as stateless people, particularly in India where many of them had been born:

Karma: In India, even though we are born in India we don't have the right of citizenship. We can only stay over there but we have a special registration form which we call RC. There's a booklet we have to renew every six months. If we don't renew that, there's a chance we may be deported to Nepal or China or whatever.

Jampa: We were considered foreign even though I was born and brought up in India. So then, in that respect, a lot of things are limited. Also we can't be working in very high positions in India, we can't become very rich or something like that.

Lack of citizenship created hardships and inconveniences for several of the participants. Yet, in one instance when citizenship was available, the participant rejected it:

Tsering: I could have very easily gotten Indian citizenship. My dad and I went to the Minister of Passports and we almost got my Indian citizenship but I said, 'No I don't want to be an Indian citizen because I am Tibetan and I should stay Tibetan.' Even though my dad said, 'no, it will create opportunities for you.' You 
know all of that.

Several of the participants thought that adopting Indian citizenship would in some ways compromise their distinct Tibetan identity. Yet on the other hand, all of the participants wanted to become Canadian citizens. This suggested that the matter of citizenship was something the participants carefully negotiated:

Tsering: [My father] said, if you don't want to take an Indian passport then he said, "I think it is important you have at least something that you can have to identify yourself.' And so because Toronto is so sympathetic to Tibetan issues and Tibetan immigrants, he said, 'why don't you go to Toronto?' So Toronto fit in with all the things we were looking for.

Jampa: Actually, one thing is that when we come to Canada as a refugee, getting immigration status is the most important thing. If we don't have that we don't have anything.

Lobsang: The reason why I came to Canada, to be honest was to get a paper [citizenship].

Among all the participants, gaining Canadian Citizenship was identified as the greatest motivating factor for migrating to Canada in the first place. One of the participants explained that obtaining citizenship was a way to insure greater security for herself and her family:

Tashi: I feel much more protected because in India, you don't feel protected. I have two children, my parents, my sisters and my husband. And I wanted to settle in a place where I feel secure and my children and my family are protected, eventually. 
Aside from greater security, a few of the participants saw Canadian Citizenship as a means through which they could connect more closely with Tibet. Many felt Canadian citizenship would provide them greater mobility, and greater status which would make visiting Tibet possible:

Karma: For Canadian citizens, they can go to different countries and they have more power. If you are Canadian you can even go to Tibet and you can go to poor places and help them. That is one of the biggest advantages to be a Canadian citizen.

Tsering: I haven't seen my Tibetan parents for like 10 years now. So for me to have a passport so I can now say, okay now I am a Canadian Citizen, and I can go back home as someone else. So that was the driving force behind why I wanted to be in Toronto.

Participants often equated citizenship with the notion of transformation.

Citizenship allowed individuals to transform from a state of rootlessness and insecurity to a state of security and stability. Adopting Canadian Citizenship, unlike Indian Citizenship was not seen as something which compromised participants' cultural integrity. Rather, it was seen as something that could enhance an individual's cultural identity and strengthen connections with Tibet.

\section{Strategies of Hybrid Acculturation}

Internal concepts. Just as participants carefully negotiated issues such of Citizenship, so too did they carefully negotiate the different cultural terrains they encountered in the various countries they had lived in. When asked to conceptualize Tibetan identity or "Tibetanness" the participants often described it 
as a notion that was fluid and not fixed. Most of the participants could describe the ways in which their own cultural identities had transformed as result of exposure to different cultures and how they adopted many non-Tibetan cultural traits and practices as their own. Cultures that might otherwise seem foreign became familiar and constructed part of their own identity:

Tsering: I have different influences in my life, different cultures. Indian obviously and Tibetan because I was born with it. Even in India, I speak their language, I follow every tradition, culture, everything of India. My friends say I wear Indian clothes all the time.

Tashi: Getting exposed to another culture, also has gotten to me. I think I have a lot of the attributes of an Indian too. I was born in India, went to an Indian university, I eat Indian food, I watch Indian movies. So that's part of the culture. If I see an Indian person walking down the street I feel like I knew this person. That's how much I feel about being an Indian, even if biologically I am not Indian but I do have cultural traits of an Indian too. I can't deny that fact.

Some of the participants suggested the transformations of cultural identity were an inevitable part of the acculturation process. Two participants credited greater mobility and opportunities to study abroad for shaping their perspectives:

Jampa: Now on cultural preservation, I believe in transformation. The world has come a long way since the time, since the early days. In the last century it has transformed a lot. In my parents time it was hard to imagine you would be in Toronto at some point in your life, or in England or in the United States or in any other part of the world right? But now you can be anywhere at any time. And that's why in terms of culturally, a lot of many things are changing. 
Lobsang: When I went to the UK for my further studies that's how I got an opportunity to move around the world and to see cultures from different perspectives. I studied in America, I studied in Canada and in Europe, and from all those experiences, one thing I can tell you is that we all are different. That's why we are learning from each other. But on the other hand we are all human beings. We all want happiness to be honest.

Even one participant who had moved less frequently and who had not studied abroad, credited his exposure to different traditions, practices and belief systems for shaping him positively:

Karma: In different cultures I learn a lot of different things. Because when I was in India I lived among Tibetans and lived with Tibetan culture, and when I came here I was exposed to another culture.

Although the participants said their cultural identities were constantly in flux and open to various influences, they all agreed that maintaining their Tibetan identity was of crucial importance to them. Although participants said it was valuable to be exposed to and even adopt other cultural influences during settlement, they all maintained that one's own distinct Tibetan identity should not be abandoned. For this participant, striking the right balance meant choosing an acculturation strategy of integration:

Lobsang: For myself, preserving the culture is one of the entities of being successful. You can be a doctor, you can be a lawyer, but if you can't hold your background, if you don't know where you came from, if you don't know your values and your identity it's very difficult to sustain within the society and in your whole life. So preserving culture on the one hand and adapting to Western culture on the other hand works 
very well. It's like two sides of the same coin.

As participants discussed their own conceptualizations of Tibetan cultural identity and Tibetanness, they were asked to describe whether Tibetan identity was comprised of any essential components. Participants consistently identified language and beliefs as the two main components which comprised Tibetan identity:

Jampa: Culture I think is your language. Your spoken and written language. That's something you need to preserve and for the Tibetan people they consider the Buddhism that has flourished in Tibet for a long time, they consider it more spiritual, something very precious. I also think that is something that is important to keep.

Karma: [Being Tibetan] doesn't mean eating a certain food and praying a certain way. If I say I am Tibetan, it is better for me to have a basic knowledge of Tibetan Buddhism because this is the identity of the Tibetan.

Lobsang: But then, one has to understand, preserving your culture doesn't mean you pray all the time. You can preserve your culture in a different way in a different form. When you talk with your fellow Tibetan, when you speak Tibetan instead of English, that's one of the forms of preserving your culture.

The participants all subscribed to the idea that knowledge of Tibetan buddhism and the ability to speak Tibetan were important elements which linked them to other Tibetans around the world. Detachment from one's belief system or losing the ability to speak the Tibetan language was viewed as something detrimental to cultural preservation efforts on a whole. 
Jampa: Because in Tibet itself, we are becoming a minority and Chinese are coming in there and setting up their schools. Now the younger generations in Tibet can speak Chinese fluently but cannot speak our Tibetan language. Even in India, we go to modern universities, but Tibetan is only given up to class 12 . After that we don't study Tibetan and its only limited for monks and nuns to study. So in a way the language is already in a stage of decline.

The participants who were parents expressed a particular concern

that younger generations born and raised in Canada would

eventually lose these aspects of their cultural identity:

Karma: I heard a lot of my wife's friends and my friends.

The parents are here and their kids are coming from India and Nepal. And after few years the kids don't speak Tibetan. I've seen a lot of young kids who don't speak Tibetan, they speak English. The parents are quite worried about that saying the kids are not speaking Tibetan. But then I think, the parents can do a lot about that. Meaning when the kids come home they should speak Tibetan. This is not just happening among Tibetans, it's happening among Indians and Chinese also. That's I think what some parents are worried about.

Another overarching theme which the participants agreed was quintessential to maintaining Tibetan cultural identity was participating in the Tibetan struggle for independence. One of the participants, a mother of two children who were still living in India, spoke candidly of her concerns about bringing her children to Canada. Her goal was that her children successfully acculturate yet not lose sight of the Tibetan struggle: 
Tashi: A part of me has this fear. I honestly want them to be more Tibetan than anything else. Maybe because I feel so stateless, I feel so unprotected. My country is directly controlled and we have to do something, that's part of the movement. So I want my children, even if they do nothing as an obligation as a child to me, but towards my country I want them to be a good Tibetan, a good human being. So I am thinking they might have many traits, like Canadian cultural traits, but if a part of them, they could maintain that [Tibetan heritage] I'll be happy.

Conceptualizing Tibetan identity lead to the discovery that participants understand that even the so-called essential facets of Tibetan cultural identity are open to interpretation and re-interpretation. During the settlement process it is possible for language, belief systems and even one's political perspectives to undergo shifts and transformations as well:

Jampa: For us, Buddhism is more flexible, the way we look at it is more flexible. Everything is impermanent. Even our own culture is impermanent. So in a way there are no steadfast rules, that have to be done this way. It can change.

Tashi: I can't stop things from changing right? If things change, [my children] will be in contact with people from other cultures. I cannot stop this trend, but all I can do is facilitate and put the traits in them because l'll be staying with them, so I'll make sure they have all those things; speak Tibetan, what does it mean to be Tibetan, and what is it you can do to make a difference to your country.

Participants were able to identify the components which they personally felt were the most important to maintain and preserve in terms of cultural identity and 
these were language, belief system and the political plight. Yet they also felt how one chooses to practice and express their culture was up to the individual and that cultural integrity was not compromised when one integrated into a new society.

\section{Cultural Expectations}

As participants recollected their settlement experiences, many of them described the inter-generational and cross-cultural conflicts and confusions they had encountered specifically as it related to cultural expectations. Although the participants themselves said they did not accept a rigid definition of Tibetanness or Tibetan Identity, some of the other individuals they interacted with did. The dimension of gender was also found to play a major role in this area. Female participants had encountered more instances of having their actions, behavior or attitudes scrutinized by fellow Tibetans than their male counterparts. For Tsering,

a young woman in her late 20 's, dating a white man transgressed many of the expectations some people in her community had of Tibetan women:

Tsering: So for me it was no big deal dating a white guy because we were best of friends. I didn't look at things and say, 'Oh my god, he's white, what am I going to do?' I didn't look at it that way. I loved him, he loved me and we started seeing each other. And then my friends started saying, 'Oh my god, you're dating a white guy!' You know it's a huge taboo right. And I am a person who is least bothered by what society or a community thinks but when you live in a community people will talk, this is how life is. So because I live in Jameson which is the Tibetan hub and the Tibetan hood, we would go and 
walk and you know, go to restaurants and every single day we go, there would always be people who would turn around and do a 360 and look and make comments and stuff. But I don't get upset or anything.

But one time I was in a restaurant and he was with me and someone I know, someone I've helped before, he came up to me and said, "I always thought you were a really nice girl, but I am really disappointed that you are dating a white guy.'

Another female participant described some of the intergenerational tensions she had encountered with respect to the role daughters play in the Tibetan family:

Tashi: [My parents] always expect that I take care of them until death, that I pull my responsibility as a daughter at any cost. They expect me to do that, and I have to fulfill their expectation. But I cannot expect the same thing from my children, because things are really different now. I was not as much exposed to different cultures as my children are exposed. So even if my son is gay or marrying a black girl, you know, I don't have that much of a problem as long as they maintain their Tibetan roots like knowing their country, knowing their parents heritage. These are important things I want my children to know, and be part of.

Participants not only encountered cultural expectations from family and community members, they often had to contend with the misconceptions nonTibetans in the receiving society had of them. As racialized minorities, the participants were often prone to stereotypes. In some instances, individuals they encountered had very essentialized or exoticized notions of Tibetan people.

Participants described incidents when other people had expected them to act or behave a certain way. When they did not meet these expectations, people expressed a sense of shock or disappointment: 
Tsering: I think a lot of people here think if you're

Tibetan, you're all about niceness, compassion, peace, meditation which is obviously one of the most important aspects of being a Tibetan, but that does not necessarily mean that we would reflect that in our day to day life every day. We're all human beings, we all make mistakes. We have good days we have bad days just like anybody else. Sometimes when I go to work, I also have my off days. I have a really short temper, and when I get pissed off, I really show it. And people go and like...once they said, 'Tsering! We didn't expect this from you.' And I said, 'No, I am a normal human being, I have my days like you have.'

Tashi: I do have some traits that are positive, and might be in close proximity to what they think but there are certain expectations that are different, that's all. Like, I don't have a problem talking about sex things, I don't have a problem talking about politics. People find it so, 'You're so open, you're talking about all these things. But that's not so Tibetan!' (Laughs).

One of the participants said when individuals had little knowledge about Tibetan culture, they would instead make presumptions and sweeping remarks about Asians more generally:

Karma: Oh yeah, yeah. These kinds of things they happen a lot. When people see me and when I say I am Buddhist, a lot of people say, 'do you know kung fu? Do you know martial arts or something like that?' A lot of people ask me that. Then a lot of people ask, 'are there any houses in Tibet?' Like that. And others say, 'do Tibetans take baths?'

Some of the participants were more frustrated than others when it came to dealing with these popular cultural stereotypes. Some participants found it 
surprising such generalizations seemed so pervasive. One participant explained that being type-cast in this way reduced people with unique voices and identities to symbols and representations:

\begin{abstract}
Tashi: When I was living in India I used to hear things like 'foreigners go ga-ga over Tibet.' They think that they are so exotic and so deeply spiritual and all those things. I think it is because of the Dalai Lama because he is projected. He is the epitome of those ideas. It is very common to generalize. Do you expect me to be like Dalai Lama? No way!
\end{abstract}

As this participant explained, the generalizations people had about Tibetan people and Tibet were largely the byproduct of the images projected by the Tibetan Government in Exile and popular media. Although participants admitted the qualities often associated with Tibetans were by and large positive, traits such as kindness, peacefulness and spirituality, these assumptions nevertheless had a way of distorting reality, reducing complex individuals down to simple, onedimensional characters. Though rather than conforming to and reinforcing these particular images, participants often confronted and challenged them by engaging in dialogue with people making the comments. In some instances, participants even rebelled against the expectations and the so-called cultural norms of people in their own community by engaging in close relationships with non-Tibetans, and not subscribing to the ideals and values expected of them.

\title{
Push and Pull Factors that Influence Strategies of Acculturation
}

Navigating new cultural and social territories was often rife with challenges 
for participants settling in Canada. Aside from the changes and reconstructions their own cultural identities underwent during the settlement stage, most participants reported encountering hardships in terms of finding employment, separation from family members, and dealing with bureaucratic barriers to integration. Participants spoke about these challenges in terms of the emotional, psychological and financial toll they took.

Familial separation and feelings of displacement

Settlement was especially trying due to prolonged separation from loved ones:

Interviewer: What was the most challenging thing you remember dealing with when you first arrived in Canada?

Tashi: That I was separated from my children, from about 2006 I didn't see them until now. That's the most challenging part. To be away from your children when they are growing up and you are not there. When they are growing up and they needed you. But I guess the family knew that was the sacrifice one has to do. And I am the eldest one in the family.

Interviewer: What would you say was the most challenging part about moving here? Lobsang: A little bit of homesickness. Because I left behind my home. So yeah, a little bit of homesickness. Researcher: And who did you live behind in Nepal? Lobsang: My parents. My brothers.

One participant described experiencing a type of exilic longing for Tibet. Although she had left her family and Tibet at a very young age the 
detachment

from her childhood home pained her to this day:

Tsering: I often end up crying because of some of the things I hold onto so dear when I was little, when I was young, when I was in Tibet. Things that I've done, you know my house. Nothing is there you know, everything is gone. Everything has changed. So, I have nothing I can hold onto, nothing I can call my own in Tibet. So for me, it's like a dream, those 8 years of my life in Tibet, for me it looks like a dream.

\section{Lack of Credential Recognition as a Barrier to Settlement}

One of the primary challenges participants struggled with upon arriving in Toronto was finding employment which matched their credentials and experience. Although this was a research theme that was lacking in the literature review, it emerged as a very prominent research theme in this study. Participants reported having similar experiences to those of other skilled newcomers arriving in Canada in that finding employment which matched their skill sets and education was incredibly difficult to achieve. It was discovered through conversations with participants that regardless of their education and qualification levels, barriers to employment were a constant hurdle they all encountered:

Tashi: The first thing I found really challenging is to find a job that suits my qualifications. And the process was so difficult. Getting a job as a teacher is really difficult. You end up feeling very out of place even with your qualifications. You're asked to do this and do that even after 12 years of practice and you're ready to practice. So I had to change from teaching to nursing. So I am 
doing my nursing at the moment which is very challenging. Very much a contrast to what I did before. But l've shifted everything in order to make a future for myself and my children.

Jampa: Finding a job is a little bit hard. Especially in my case because I changed my line, because back home I was an engineer. In the United States I did my MBA, right after graduation I came here. I don't have an experience in the finance field. Canadian employers are mainly looking for experience. They are not giving that much importance to educational qualifications. In India people go through college, then university. They complete their degrees fast and first, then they go to the job market. In India they give more importance to education qualifications and then the prestige of the institution where you graduated, whereas in Canada, it seems a little more arranged towards experience, and I didn't know that.

Karma: They say the first thing to finding a job in Canada is networking. I feel if I have friends then I have a higher chance of getting a job in Canada. Even though you don't have a good resume.

Research focusing on foreign credential recognition in Canada suggests that the work experience and years of schooling newcomers accumulate prior to arriving in Canada is valued much less than the experience of their native-born Canadian counterparts (Ferrer \& Riddell, 2008, 187). Indeed, the experiences of participants in this study validated these findings. Not only did participants discover that their credentials seemed to be of less value, in some instances they described feeling as though their credentials were valueless. One of the greatest frustrations participants expressed was the prospect of having to complete a Canadian high school diploma in order to meet certain English language 
requirements to be eligible for training programs. This was particularly upsetting for participants who had attained university or graduate degrees abroad. One participant expressed his frustration at seeing friends having to go through this process:

\begin{abstract}
Jampa: Most of them don't care about the degree that they earned in their home country because they didn't put that much effort to earn it right? So it's okay if you have to start going to high school, it's okay. Ninety per cent of the youths educated with graduate degrees come here and start all the way from high school here again, then most go to nursing. Because in nursing they can be guaranteed that they are going to get a job. But in my case, it's a little bit tough. I'm still holding onto that thing, my degrees at home and in the United States. I gave so much effort and time into that. I almost wasted my youth to get that! I don't want to start from high school again and be a nurse. That's why after coming to Canada, and after three years I am still looking for a job in my own field.
\end{abstract}

The problem of not having their qualifications recognized in Canada reinforced many of the challenges many of the participants were already experiencing in terms of adjusting to a new environment and integrating. Participants were often open to making the cultural accommodations expected of them as newcomers to Canada, and were eager to participate fully in their fields of expertise. However, upon arriving in Canada they expressed disappointment and frustration with the barriers which seemed to hinder rather than help them acquire meaningful employment in their fields. 
Coping with these types of challenges was particularly difficult for participants who had limited support systems available to them during settlement.

Participants often reported feeling a sense of isolation upon moving to Canada which only exacerbated their already trying circumstances. One participant explained the reason why she had decided to quit her college program in Toronto after only a short period of time:

Tsering: I felt like oh my god, I don't belong here. I felt like someone who is an outsider. You're being watched, you're being judged you know. And all the time I was going through culture shock. Coming here, everything is new. You know it's not home. Your heart is not here, you've just left your home and family and you don't feel at ease here so one of the reasons why I left the school was because I was the only Asian student and I didn't want to be that outsider. And I cried and told my Dad I don't want to go to this school. Because I was not able to learn anything. I would just sit quietly in the back, and not do anything.

Most revealing in these conversations were the various ways participants coped with these challenges; the detachment from family, the feelings of isolation, the challenges to employment, and the culture shock. Despite the hardships they had undergone, it was discovered that participants had developed a resilience, grounded primarily in their belief systems and culture which provided them with the motivation and strength to carry on with the settlement process. When participants were asked how they managed to cope with the challenges of settlement, nearly all of them credited their Buddhist beliefs for providing them which much needed support and strength: 
Jampa: Challenges are always there. We are used to it. We are Buddhists, our religion plays a part. In buddhism there is not so much of great outlook of life as such. In Buddhism it says you need to understand and know suffering. Your life is called Samsara. It's the suffering you have to go through. You have to understand that form of life and you have to get out of it.

Tashi: Even at school if things don't work the way I want, I get really frustrated and really angry but I don't hold that anger so long. After a few minutes, I forget. I forget stress. But that's because I hold onto my Buddhist belief dealing with the karma, and this really helps.

Karma: [Buddhist practice] has helped me a lot. I am not saying I am the greatest person, but some people they say, 'Oh my god I went to six or seven interviews and I didn't find a job! What am I going to do?' You know, becoming so agitated. I don't feel that way because I feel patience is the most important part.

For some of the participants, the ability to practice their Tibetan culture, and traditions provided them something familiar in an otherwise foreign landscape.

They said their culture and cultural identity anchored and grounded them during turbulent times:

Tsering: Always in my dark and low moments, when I am happy I feel my most comfortable taking that refuge in things that are Tibetan.

The cultural networks and connections which participants maintained with other members of the Tibetan diaspora in Toronto also served a useful purpose. In the case of one participant, these relationships created much needed social capital 
providing financial assistance, and social support when access to settlement

services was limited or lacking:

Jampa: But because I have friends living here, my schoolmates living here for a long time, who had come here before me, they are more settled here. So when I face problems I can turn to them, especially, when I first came here, all my money was exhausted. I borrowed money from my friends, otherwise it is hard to find money. And um, if I need help or anything like that, emotional, like when you move to a new society you need friends, closeness. That relationship should be there so, I turn to my friends.

Participants were even able to draw from their experiences as refugees to gain a sense of perspective when confronting settlement challenges:

Tashi: Coming to Canada is just one part of the struggle. It's not such a huge struggle. I keep hearing from my friends how they struggle, and if I look back my struggle is nothing compared to my parents. My mother went through a lot of struggles in terms of physical abuse, mental abuse, and all these abuses. Some people say you carry what your parents have, and you also feel the trauma. I feel so sad about my parents how they went through all these things. They fled from Tibet on foot, and once they came to India, again they had to flee because of the Chinese and Indian war. So all through their lives they have to go through so much struggles. My struggle is nothing compared. So I really don't get depressed. Seriously! I say in life I will never go crazy because I control myself and can get through those crises.

Karma: Whenever I am having a hard time I always realize I am the luckiest person. I have come to Canada, such a great country. Yes, I do have some problems finding a job, that is a problem. But I think about brothers and sisters who live in Tibet, they are 
suffering a lot under Chinese pressure. They're being imprisoned, they're being killed. And whenever I have a hard time I look around and try to compare myself to other peoples' problems or suffering. So I realize my problem is very small. I will find a job eventually.

\section{Acculturation Strategies}

It was evident through discussions with participants that as they moved through the settlement process, they were adopting an integration strategy of acculturation. They weaved together various cultural influences, their own Tibetan identity, with those various cultures they encountered in and en route to Canada:

Tsering: Whatever Tibetan cultures I have inside of me, like influences of Buddhism, whatever has shaped my attitude towards life, if I carry that wherever I go, people will immediately know the distinct characteristics of where you come from. India has provided me with the opportunity to find myself and stay on solid ground. And coming here [to Canada] has further enhanced that. Now it is just adding to my cultural milieu.

Participants looked upon their own cultural identities and saw them as fluid. Their attitude was that it was possible to select the aspects of their cultural heritage and the culture of their new country and mesh them in ways that suited them.

These fusions were seen as beneficial and a part of positive personal growth:

Lobsang: I followed the Dalai Lama's speech, his advice and at the same time am progressing my personal life by adapting to Western Culture.

Tashi: My parents generation, they of course tried to maintain that you have to marry Tibetan, you are 
Tibetan, you have to offer prayers, you're Buddhist.

Everything surrounds around Tibetan culture. But I am second generation or third generation. I don't expect my children to be in that you know, unique culture. I want them to see the world and find their own objectivity. Of course I want them to maintain all the values and principles of being a Buddhist or Tibetan, I do really want that, but I don't have as much expectation as my parents' had.

It is evident that for these participants, adopting an integration strategy played a critical role in the journey towards successful acculturation and settlement in Canada. The process of integrating involved balancing and harmonizing sometimes competing cultural elements. Participants also equated successful settlement with their own ability to remain resilient in spite of the challenges and barriers they were confronting. Most of the participants credited their own belief systems, culture and social networks for providing them with the much needed skills, social capital and encouragement required to survive the often harsh conditions that greeted them in Canada.

\section{Chapter 5: Discussion}

The sample for this study represented a diverse mix of experiences and perspectives that made for very dynamic interview discussions of cultural identity and settlement. Individuals discussed the notion and their perceptions of Tibetan cultural identity and specifically discussed the ways in which their cultural linkages, practices and belief systems influenced their acculturation experience. Individuals identified what aspects of their cultural identity they valued the most, 
how these interpretations differed from elders in their community, even how they may have clashed with the assumptions of people they met in Canada. In some instances, the female participants discussed the role of gender as it relates to cultural expectations. There was also discussion about the types of settlement challenges individuals encountered and the ways their cultural identity would intersect with these challenges. Finally, the types of acculturation strategies individuals adopted were discussed and examined.

The in-depth interviews with participants revealed a wide spectrum of experiences, as well as their hopes and aspirations for their lives in Canada. Similar themes that were explored in the literature review such as cultural identity, citizenship and cultural expectations surfaced in this research as well. Yet, in allowing the study participants to direct the conversation, rather than leading them, the discussion charted new territories. Participants spoke about confronting tremendous barriers in settlement, feeling unmoored in a new country, and experiencing the hardship of prolonged detachment from their loved ones. It also became evident that their families' refugee legacy had left a deep and lasting impact on them as well. What this indicates is that the residue of trauma, caused by forced migration, can be apparent even in later generations and can be felt in many different ways.

Many of the studies explored in the literature review suggest that Tibetans in exile will adopt limited strategies of integration or chose strategies resembling separation because keeping a distinct Tibetan cultural identity intact is of utmost importance. My research on the other hand, while finding that participants did 
indeed adopt strategies of integration, found that maintaining a distinct cultural identity was not as much a priority for participants as it was in other studies. The argument that individuals could not and would not fully acculturate into a new society because of concerns of cultural loss was found not to be the case with Tibetans settling in Toronto. There was an awareness among participants that the Tibetan culture faces a very real threat of cultural destruction. Yet this fear did not translate into a desire to culturally conform to a fixed construct of "Tibetan National Identity." Instead, individuals maintained what they felt were the essential aspects of their cultural identity; their beliefs, language and political activism wherever they resettled, and at the same time adjusted and adapted to the cultures in their new environments. Moreover, participants often found many elements of the receiving country's cultures to be completely compatible with their own.

This study also found that participants were less influenced by larger cultural institutions, namely the Government in Exile and community organizations, than was found in previous studies. Individuals chartered their own settlement paths, making their own strategic decisions about citizenship, interpersonal relationships and cultural preservation in accordance to their own needs and desires. Thus, these findings revealed the personal agency of participants. This study confirms what Verkuyten and de Wolf argue, which is that individuals are not inevitably and simply "marked or 'molded' " (Verkuyten \& de Wolf, 2002, 389). They are instead active participants in the construction of their lives.

Indeed, this study revealed other variables which were influencing the 
acculturation process of participants. One aspect that was lacking in several of the other studies about Tibetans in exile was an in-depth examination of the life histories, and personal settlement experiences of subjects. Delving into these life histories revealed important variables such as the systemic barriers and the discrimination and marginalization refugees often encounter in the receiving country. In this case, these variables were proven to be important factors which greatly influenced the settlement experience and by extension the acculturation strategies individuals adopted. Maintaining and preserving their cultural identity and cultural connections during acculturation proved useful in the sense that it could offer participants a sense of support and comfort, making them more resilient to the types of frustrations and crises they encountered during settlement. As Clifford (1994) explains, re-creating Tibetan culture in exile might actually assist individuals who are coping with the "brute facts of physical survival in host countries" (Clifford, 1994 as cited by Harris, 1999, 14).

\section{Assessing Berry's Integration Strategy}

The research findings in this study validate Berry's model of acculturation, though his strategy of integration was too narrow in some aspects. For instance, although he theorizes that the integration strategy is the most successful path of settlement because it allows individuals to find balance through accepting and rejecting new and old cultural traditions and behaviors, it does not necessarily take into account other variables which lead to positive settlement. In this case study, participants found that blending cultural practices, their own with those in 
the receiving country, actually aided their integration. However, their cultural adaptation could only take them so far.

Barriers to Settlement: Credential Recognition

The most obvious theme lacking in the literature reviewed, but which consistently emerged throughout participant interviews was the lack of credential recognition which individuals encountered upon arrival in Canada. The fact that this theme was noticeably absent from the research of other authors who studied Tibetan diasporas in other countries, suggests that the issue of credential recognition is more significant in Canada. In this case study, participants neither underestimated nor shied away from discussing the way lack of credential recognition had impacted their settlement experience. The inability to have foreign credentials recognized, the inability to gain retraining and mentorship in one's field of expertise and a lack of employment support networks not only hindered the settlement process, it appeared to stall it outright for study participants.

\section{Chapter 6: Study Strengths, Limitations and Further Study}

One of the greatest strengths of this study was that it helped fill the research gap of Tibetan refugees living in Canada which may in turn help lay the foundation for further research into this particular segment of Canada's diverse population. This study was also able to highlight the ways in which skilled 
refugees, not just skilled immigrants, encounter barriers to employment, in addition to an undervaluing of skills and education.

This research provided a more complex lens through which to view acculturation, for not only are individuals influenced by in-group and receiving country expectations, they are also shaped by systemic barriers to employment and training. The small sample size allowed for both intimate and in-depth discussions with study participants, and allowed the researcher to collect their personal histories and honest, and thoughtful reflections on their settlement journey.

As in most exploratory studies, there were limitations with this research project. At the start of the project, it was important to identity and to be conscious of any potential "blind alleys" which might arise during the data gathering stage. For instance, in order to avoid misinterpretation through translation and in order to more fully engage with study participants, it was important that they be fluent in the English language. This limited the participation of individuals to only those who were fluent speakers of English and or had received extensive English language training. As a consequence, nearly all the study subjects had some form of post-secondary education. This meant the study overly-represented highly educated refugees many of whom had at some point migrated from a major urban centre to Canada (with the exception of one participant). What this study lacked were differing perspectives including more rural perspectives and perspectives from different socio-economic classes. Ultimately, in order to avoid any communication difficulties it was essential to limit the scope of participants to 
English speakers despite the fact some very important and vital perspectives would be noticeably absent.

Furthermore, in limiting the study sample to only those individuals living in the Parkdale neighborhood of Toronto, I as the researcher was fully aware that perspectives of individuals living outside this zone would not be accessed. That said, by narrowly focusing on a neighborhood which is known in Toronto as a socalled ethnic enclave or cultural hub due to its large population of Tibetans it was possible to gain interesting insight into the ways individuals interacted and moved through a landscape that was both culturally familiar and foreign.

\section{Recommendations}

Echoing what numerous researchers, activists and policy makers, have been calling on for years, this study reaffirms that there needs to be greater mechanisms in place in Canada that are designed to aid and assist newcomers to acquire gainful employment in their professions. While it is important for individuals to be able make cultural adaptations, it is equally important for credential recognizing institutions such as governing bodies in the private and public spheres, to adapt as well. As this study, and others have shown, the greatest obstacle to settlement for foreign-trained professionals is not the inability to culturally acclimatize, but rather the inability for these individuals to make use of their skills, training and knowledge in meaningful and productive ways. As this study examining one slice of the Tibetan population in Toronto has shown, these 
types of systemic barriers apply not only to so-called "traditional immigrants" who come to Canada, but also refugees.

Participants in this study had for the most part, all the educational qualifications and work experience they needed in order to secure employment. Yet upon arriving in Canada, the discovery that these credentials were not recognized proved to be a greater shock than anything they encountered culturewise. While waiting for their refugee hearings to proceed, sometimes for months and sometimes for years, participants unable to work in their given field found themselves toiling away at menial jobs or simply unemployed. There was a general consensus among those interviewed that time was wasted and would have been better spent gaining Canadian work experience, gaining skills retraining, upgrading credentials and or even doing internships in their fields. Being stuck in this state not only hindered their settlement, it had far-reaching consequences for their families back home who are financially dependent on them. Furthermore, given that the social and financial capital of refugees may be limited compared to that of their immigrant counterparts, it is even more crucial to recognize that as a population, this demographic would stand to gain the most if mechanisms and programs were in place which were designed to help refugees acquire the skills and experience they need to work in their area of expertise.

Secondly, while this study attempts to offer a portrait of the acculturation and settlement experiences of one specific group in the Canadian mosaic, it is crucial for further studies like this to continue. The weakness with this study was that the relatively small sample size, limited only to one particular cultural group 
provided merely a glimpse of the types of settlement challenges facing refugees as a whole. In addition to this, this research was limited to studying the initial and early years of settlement for an individual and this also made it quite narrow in scope. Thus, it was difficult to determine the potential long-term effects that settlement barriers might pose for refugees, and indeed their families. Thus, it would be valuable for there to be research tracking the progress of individuals over the course of ten, and even twenty years of living in Canada since this would provide a more long-range perspective.

Ultimately, by examining exiled communities, specifically refugees, we can gain a better understanding of the complexities, and multidimensional variables which all factor into the settlement experience. Further research would undoubtedly aid practitioners serving refugee clients and provide a clearer sense of the type of support and most effective ways to help people experience a more positive and successful settlement experience. 


\section{References}

Adams, Vincanne. "Karaoke as Modern Lhasa, Tibet: Western Encounters with Cultural Politics." Cultural Anthropology 1, no. 4, (1996): 510-546. HYPERLINK "http://www.jstor.org/stable/656666" http://www.jstor.org/stable/656666" (accessed July 16, 2009).

Anand, Dibyesh."(Re)imagining nationalism: identity and representation in the Tibetan diaspora of South Asia." Contemporary South Asia 9, no. 3. (2003): 271287.

Basu, Sudeep. "Interpreting the Tibetan Diaspora: cultural preservation and the pragmatics of identity." CEU Political Science Journal 4, no. 3 (Sept 2009): 419(27). Academic OneFile. Gale. Ryerson University. HYPERLINK

http://find.galegroup.com.ezproxy.lib.ryerson.ca/gtx/start.do?prodld=AONE\&user GroupName=rpu main" (accessed March 26, 2010)

Berry, John. "Acculturation Strategies and Adaptation." In Immigrant Families in Contemporary Society, edited by Jennifer E. Lansford, Kirby Deater-Deckard, Marc H. Bornstein, 69-82. New York: Guilford Press Publications Inc., 2007.

Betts, Alexander. Forced Migration and Global Politics. West Sussex: WileyBlackwell, 2009.

Boyd, D. "Resilience in Newcomer Families." Canadian Issues, Immigration and Families, (2006): 85-86.

Bose, Pablo. "Dilemmas of diaspora: partition, refugees, and the politics of 'home'." Refuge: Canada's periodical on refugees, Volume 23, Issue 1 (Winter 2006),: 58+. CPI.Q (Canadian Periodicals). HYPERLINK http://find.galegroup.com.ezproxy.lib.rverson.ca/gtx/infomark.do?\&contentSet=IA C-

Documents\&type =retrieve\&tabID $=$ T002\&prodld $=C P|\& d o c| d=A 144292861 \&$ sourc $\mathrm{e}=$ gale\&srcprod=CPI\&userGroupName $=\mathrm{rpu}$ main\&version=1.0 (accessed March $7,2009)$.

Cheran, R. "Multiple homes and parallel civil societies: refugee diasporas and transnationalism." Refuge Summer 2006: 3+. CPI.Q (Canadian Periodicals). Web. 30 Mar. 2010. 
City of Toronto. "2006, South Parkdale (85) Social Profile \#2 - Neighborhoods Language and Ethnicity." City of Toronto. HYPERLINK http://www.toronto.ca/demographics/cns profiles/2006/pdf2/cpa85.pdf" (accessed June 1, 2010).

Couldrey, Marion and Morris, Tim. "Introduction: Culture in exile." Forced Migration Review 6 (1999): 4.

Creswell, John., Research design, qualitative, quantitative, and mixed methods approaches. (3rd ed.). Thousand Oaks, California: SAGE Publications Inc., 2009.

Diehl, Keila. Echoes from Dharamsala: Music in the Life of a Tibetan Refugee Community. Berkeley and Los Angeles: University of California Press, 2002

Falcone, Jessica \& Wangchuk, Tsering. "We're Not Home": Tibetan Refugees in India in the Twenty-First Century." India Review 7, no. 3, HYPERLINK "http://dx.doi.org/10.1080/14736480802261459" (accessed March 27, 2009).

Ferrer, Ana \& Riddell, Craig. "Education, Credentials and Immigrant Earnings." Canadian Journal of Economics 41.1 (2008): 186+. Academic OneFile. HYPERLINK http://find.galegroup.com.ezproxy.lib.ryerson.ca/gtx/infomark.do?\&contentSet=IA C-

Documents\&type $=$ retrieve \&tab $\mid \mathrm{D}=\mathrm{T002 \& prod} \mathrm{d}=\mathrm{AONE} \& \mathrm{doc} / \mathrm{d}=\mathrm{A} 215468922 \& \mathrm{sou}$ rce $=$ gale\&srcprod $=A O N E \&$ userGroupName=rpu main\&version $=1.0$. (accessed July 23, 2010).

Graf, Shruti C., Ronald L. Mullis, and Ann K. Mullis. "Identity formation of United States American and Asian Indian adolescents." Adolescence 43, no. 169 (2008): 57+. Academic OneFile. HYPERLINK" http://find.galegroup.com.ezproxy.lib.ryerson.ca/gtx/start.do?prodld=AONE\&user GroupName=rpu main" (accessed November 27, 2009).

Harris, Clare. "Imagining Home: the reconstruction of Tibet in exile." In Forced Migration Review 6, (Dec.1999): 13-16

Hennink, Monique, lan Diamond, and Philip Cooper. "Young Asian women and relationships: traditional or transitional?" Ethnic and Racial Studies 22, no. 5 (1999): 867+. Academic OneFile. Web. < HYPERLINK http://find.galegroup.com.ezproxy.lib.ryerson.ca/gtx/start.do?prodld=AONE\&user GroupName=rpu main" (accessed November 27, 2009)

Hess, Julia Meredith. "Statelessness and the State: Tibetans, Citizenship, and 
Nationalist Activism in a Transnational World.sup.1." International Migration 44, no.1 (March 2006): 79(25). Academic OneFile. Gale. Ryerson University. HYPERLINK

http://find.galegroup.com.ezproxy.lib.ryerson.ca/itx/start.do?prodld=AONE (accessed June 23, 2009)

Hongsheng, Yang, Liao Quanming, and Huang Xiting. "Minorities remember more: The effect of social identity salience on group-referent memory." Memory 16, no. 8: 910-917. Psychology and Behavioral Sciences Collection, (November 2008), EBSCOhost (accessed March 27, 2010).

Houston, Serin, and Richard Wright. 2003. "Making and remaking Tibetan diasporic identities." Social \& Cultural Geography 4, no. 2: 217. Academic Search Premier, EBSCOhost (accessed June 29, 2010).

Klassen, Robert M. "A cross-cultural investigation of the efficacy beliefs of South Asian immigrant and Anglo Canadian nonimmigrant early adolescents." Journal of Educational Psychology 96, no. 4 (2004): 731+. Academic OneFile. Web. HYPERLINK" HYPERLINK

"http://find.galegroup.com.ezproxy.lib.ryerson.ca/gtx/start.do?prodld=AONE\&user GroupName=rpu_main" (accessed November 27, 2009).

Lewis-Watts, L. "Speaking with Families from within the 'Family Class'." Canadian Issues, Immigration and Families, (2006): 81-84.

Leung, H.H. "Settlement services for the Chinese Canadians in Toronto: The Challenges toward an integrated planning." At Work: Settlement.org. http://atwork.settlement.org/sys/atwork_library_detail.asp?passed_lang=EN\&doc _id=1002333 (accessed September 8, 2010)

Lopez, Donald. Prisoners of Shangri-la. Tibetan Buddhism and the West. Chicago: University of Chicago Press, 1999.

Meredith, Julia. "Mapping identity: Tibetans in New Mexico and their incorporation into the tri-ethnic myth." Journal of the Southwest 44, no. 1 (2002): 105+. Academic OneFile.

HYPERLINK " HYPERLINK "http://find.galegroup.com.ezproxy.lib.ryerson.ca/gtx/infomark.do?\&contentSet=IA C-

Documents\&type=retrieve \&tabID=T002\&prodld =AONE\&docld=A86469985\&sour $c e=$ gale\&srcprod=AONE\&userGroupName=rpu_main\&version=1.0" (accessed March 26, 2010). 
Migration Information Source, "Global Nomads: The Emergence of the Tibetan Diaspora," (Part I), Migration Information Source, HYPERLINK http://www.migrationinformation.org/USFocus/display.cfm?ID=693 (accessed June 1, 2010).

Netting, Nancy S. "Two-lives, one partner: Indo-Canadian youth between love and arranged marriages." Journal of Comparative Family Studies 37.1 (2006): 129+. HYPERLINK

http://find.galegroup.com.ezproxy.lib.ryerson.ca/gtx/start.do?prodld=AONE\&user GroupName=rpu main (accessed November 30, 2009).

Neuman, W. Lawrence. Social Research Methods: Qualitative and Quantitative Approaches, 6th Edition. Boston: Allyn and Bacon, 2006.

Phuntsog, Nawang. "Cultural identity and schooling of Tibetan children in the diaspora." Equity \& Excellence in Education 31(1): 36-39 (1998), Academic OneFile.< HYPERLINK " HYPERLINK http://www.informaworld.com/10.1080/1066568980310106 >. (accessed March $27,2010)$.

Robinson, Lena. "Cultural Identity and Acculturation Preferences Among South Asian Adolescents in Britain: An Exploratory Study." Children \& Society 23, no. 6 (2009), Academic OneFile. Web. < HYPERLINK http://find.galegroup.com.ezproxy.lib.ryerson.ca/gtx/start.do?prodld=AONE\&user GroupName=rpu main>. (accessed November 27, 2009.)

Rousseau, Cecile, Marie-Claire Rufagari, Deogratias Bagilishya and Toby Measham. "Remaking Family Life: Strategies for Re-establishing Continuity Among Congolese Refugees During the Family Reunification Process." Social Science \& Medicine, 59: (2003): 1095-1108.

Statistics Canada. "Ethnic Origins, 2006 counts, for Canada, provinces and territories - $20 \%$ sample data." Statistics Canada.

HYPERLINK " http://www12.statcan.ca/census-recensement/2006/dp-pd/hlt/97562/pages/page.cfm?Lang $=E \& G e 0=P R \&$ Code $=01 \& D a t a=$ Count $\&$ Table $=2 \&$ Start $\underline{R e c}=1 \&$ Sort $=3 \&$ Display=All\&CSDFilter $=5000$ \#Notes (accessed June 1, 2010).

Talbani, Aziz, and Parveen Hasanali. "Adolescent females between tradition and modernity: Gender role socialization in South Asian immigrant culture." Journal of Adolescence 23, no. 5 (2000): 615. Academic OneFile.

$<$ HYPERLINK

http://find.galegroup.com.ezproxy.lib.ryerson.ca/gtx/start.do?prodld=AONE\&user GroupName=rpu main $>$. (accessed November 27, 2009) 
Tyyskä, Vappu, "Immigrant Families in Sociology." In Immigrant Families in Contemporary Society, edited by Jennifer E. Lansford, Kirby Deater-Deckard, Marc H. Bornstein, 83-99. New York: Guilford Press Publications Inc., 2007.

Um, Khatharya. "Diasporic nationalism, citizenship, and post-war reconstruction." Refuge: Canada's Periodical on refugees, 23, no 2 (2006): 8-19.

Verkuyten, M., \& de Wolf, A. "Being, feeling and doing: Discourses and ethnic self-identification among minority group members." Culture and Psychology 8 , no. 4. (2002):371-399.

Westhues, A., Cadell, S., Karabnow, J., Maxwell, L. \& Sanchez, M. "The creation of knowledge: Linking research paradigms to practice," Canadian Social Work Review 16 (1999): 129-154.

Yeh, Emily T, \& Kunga T Lama. "Hip-hop gangsta or most deserving of victims? Transnational migrant identities and the paradox of Tibetan racialization in the USA."

Environment and Planning A 38, no. 5, (2004). Academic OneFile. Gale. Ryerson University, HYPERLINK http://find.galegroup.com.ezproxy.lib.ryerson.ca/itx/start.do?prodld=AONE>. (accessed June 23, 2009) 
Appendix I 


\section{Recruiting Participants for a Study on Tibetan Identity during the Settlement Experience in Canada}

Hello/Tashi Delek!

My name is Farha Akhtar and I am a Ryerson Graduate Student in the Department of Immigration and Settlement Studies at Ryerson University. I am currently recruiting participants to interview for a social research study examining Tibetan identity during the settlement process in Canada. This is a unique opportunity to contribute to the knowledge about the Tibetan migrant experience.

This is a VOLUNTARY study, you will NOT be paid. Your identity will remain strictly CONFIDENTIAL in the final paper.

\section{What is the Purpose of this Study?}

Tibetan people represent a large and growing community in Toronto, yet there is very

little academic research about the settlement experiences of this cultural group. The

purpose of this study is to shed light on the personal experiences of Tibetan migrants

(specifically refugees) living in Toronto. It will look at what happens to a person's Tibetan

identity when they move to a different cultural landscape, and try to settle and adapt to

life in a new country.

\section{Who is Eligible?}

- Tibetan men or women between the ages of $20-40$

- Tibetans who have moved to Canada in the last year to four years (2006-2010)

- Individuals who have come to Canada as a refugee claimant Individuals fluent in English

\section{What's involved?}

- Participants will participate in a one-hour (maximum) interview with myself, the principle investigator

- Interviews can take place either in the participant's home, a private room in the Parkdale Library or another nearby location they feel comfortable with

- Should there be a need for a follow-up interview, participants will be contacted 
and

similar arrangements will be made.

What are the benefits of Joining this study?

- Help researchers better understand the experiences of Tibetan migrants in Toronto

- A chance to help raise awareness about the challenges Tibetan refugees encounter

- To shed some light on the different ways Tibetan migrants express their identity in a

new country

${ }^{*}$ For more information about this study, to volunteer, or if you know of someone who may be interested in participating, please contact me directly by email or phone. Thank you.

fakhtar@ryerson.ca

tel: $347-255-9312$ 
Appendix II 


\section{Consent Form}

\section{Rerson University \\ Consent Agreement}

\section{Exploring themes of Tibetan Cultural Identity during the Settlement experience in Toronto, Canada}

You are being asked to participate in a research study. Before you give your consent to be a volunteer, it is important that you read the following information and ask as many questions as necessary to be sure you understand what you will be asked to do.

Investigators: This research study is being conducted by Farha Akhtar, a Ryerson University Graduate Student. This study is part of her Major Research Paper which she is doing as a graduate student in the Department of Immigration and Settlement Studies at Ryerson University in Toronto. Her research is being supervised by Dr. Carmen Schifellite who is a Professor in the Department of Sociology at Ryerson University.

Purpose of the Study: This research study is looking at the experiences of Tibetan men and women in their $20 \mathrm{~s}$ and $30 \mathrm{~s}$ who have moved to Toronto, Canada. As people who were forced to migrate out of their homeland, Tibetans who live outside of Tibet work very hard to preserve their culture. For many Tibetans, especially younger generations, Canada is the second or third country they have lived in. Each time they move to a new place, they must learn local cultures, languages and adapt to their new surroundings and at the same time, preserve their own culture and heritage, and this can be difficult. This study will look at what happens to the cultural identity of young Tibetan people during the settlement process in Canada. The purpose of this study is to get a better sense of the unique challenges facing this group of people. This study is looking for five Tibetan men and women who have come to Toronto in the last year to four years. The investigator is looking for English-speaking Tibetans who can be interviewed about their experiences moving to and living in Toronto.

Description of the Study: As a participant in this study, you will participate in an initial individual interview no more than one hour long. You may also be asked to participate in a brief interview follow-up which will be maximum one hour in length as well. The interview will be done alone with Farha Akhtar the principal investigator. In the interview, she will ask you questions about your life, and your experiences moving to and adjusting to life in Toronto. Interviews can be conducted at the participant's home, or in a quiet location close to their home.

Some of the types of questions you will be asked are:

-What was your life like before you moved to Toronto?

-What is the most difficult thing about adjusting to life in this new city? 
-How important is preserving your Tibetan culture?

-What do you think is the most challenging thing about trying to preserve your culture in Canada?

\section{What is Experimental in this Study:}

None of the procedures used in this study are experimental in nature. The only experimental aspect of this study is the gathering of information for the purpose of analysis.

\section{Risks or Discomforts:}

The investigator recognizes that some participants may be very busy with other challenges in their life, (ie: finding a job, helping their family, applying for education) and may not feel they have time for this study. The investigator wants it to be easy for people to participate in this study so she will make what efforts she can to accommodate the needs of participants. The investigator will try to conduct interviews when and where it is convenient for the participant. She is also willing, when possible and to a limited degree, assist participants with some of their settlement matters as long as it does not compromise her role as an investigator or the study itself.

Also, some participants may feel uncomfortable or shy sharing details about their lives with the researcher. They may also have concerns about speaking about the people in their lives, whether it is teachers, friends, family members, or members of their community. The researcher recognizes this and participants are assured, all information they provide is kept confidential. The names of people they describe will not be revealed. Participants do not have to answer any questions that make them uncomfortable. At any time during the interview or group session, he/she begins to feel uncomfortable, he/she may stop participating in the study either temporarily or permanently. Also, the identity and real names of participants will not be used in this study.

Benefits of the Study: There is very little research about the unique experiences of Tibetan people who moved to Toronto even though the population of Tibetans in the city is in the thousands and continues to grow. There is also very little research about younger Tibetan people in particular and especially Tibetan women in Canada. This study is intended to help other researchers and even settlement agencies understand the unique challenges facing younger generations of Tibetans so they can tailor programs and services to better help this population. There are no direct benefits the participants can expect to receive by being involved in this study, only that their participation may help raise awareness about issues facing Tibetan refugees in Canada.

Confidentiality: The identity of the participants in this study will be kept confidential. Only the principal investigator and the study supervisor will have access to the data collected during interviews. An audio recording device will only be used to document the interviews and statements made during the group session. These recordings will be transcribed electronically using an audio recorder. Both transcriptions and audio 
recordings will be stored in a computer secure hard drive which is password protected and which only the principal investigator has access to.

This data will be analyzed by the principal investigator. All recordings will be destroyed upon completion and grading of the research study. Interview subjects will not be able to review or edit the tapes prior to publication.

The Confidentiality of all study participants is promised and no identifying information will be used in all reports and publications arising from this study. Confidentiality is provided to the fullest extent possible by law, which in Canada is a maximum of 10 years.

Incentives to Participate: Participants will not be paid to participate in this study.

Costs and/or Compensation for Participation: There are no costs associated with participating in this study. However, there is possibility of compensating participants who incur childcare costs to participate in interviews. Participants who require making childcare arrangements to accommodate interviews should notify and discuss compensation with the principal investigator.

Voluntary Nature of Participation: Participation in this study is voluntary. Your choice of whether or not to participate will not influence your future relations with Ryerson University OR with the researcher. If you decide to participate, you are free to withdraw your consent and to stop your participation at any time without penalty or loss of benefits to which you are allowed.

At any particular point in the study, you may refuse to answer any particular question or stop participation altogether.

Questions about the Study: If you have any questions about the research now, please ask. If you have questions later about the research, you may contact.

Farha Akhtar

fakhtar@ryerson.ca

TEL: 347-255-9312

If you have questions regarding your rights as a human subject and participant in this study, you may contact the Ryerson University Research Ethics Board for information.

Research Ethics Board

c/o Office of the Vice President, Research and Innovation

Ryerson University

350 Victoria Street

Toronto, ON M5B 2K3

416-979-5042

\section{Agreement:}

Your signature below indicates that you have read the information in this agreement and 
have had a chance to ask any questions you have about the study. Your signature also indicates that you agree to be in the study and have been told that you can change your mind and withdraw your consent to participate at any time. You have been given a copy of this agreement.

You have been told that by signing this consent agreement you are not giving up any of your legal rights.

Name of Participant (please print)

Signature of Participant

Date

*Signature of Participant Consenting

Date

to have interview audio-recorded

Signature of Investigator

Date 
Appendix III 
Interview Guide

Interview Guide for Open-Ended Interview Sessions with Tibetan Research Participants

(Principal Investigator: Farha Akhtar)

Introduction: The Following questions are a sample of the types of questions I will be asking study participants during the initial interview session. These questions are designed to be a launching point from which wider discussions can develop. My aim with these questions is to gain a sense of how my participants feel about being "cultural ambassadors" of Tibet and the importance they ascribe to maintaining cultural identity during the settlement process, I hope to get a sense of what Tibetaness means to them and a picture of what actually causes cultural identity to transform during the settlement process. I hope to also gain insight into the types of challenges associated with settlement. Some of the open-ended questions include:

-What was your life like before you moved to Toronto?

-What can you tell me about your life in the country you were in before coming to Canada?

-What brought you to Toronto and to Canada?

-What were you taught as a child about your Tibetan heritage?

-What type of activities did you do to preserve your culture?

-What did your parents and elders tell you about the importance of preserving your culture?

-What does being Tibetan mean to you?

-How important is preserving your Tibetan culture?

-What is the most difficult thing about adjusting to life in this new city? -How easy or difficult has it been to preserve your culture in this new place? -What types of things do you do in your own life to preserve your culture? -How similar or different are the ways you preserve your culture from your parent's or grandparent's generation?

-What do you think is the most challenging thing about trying to preserve your culture in Canada? 
